\title{
A Review on Structural Behavior, Design, and Application of Ultra-High-Performance Fiber-Reinforced Concrete
}

\author{
Doo-Yeol Yoo'), and Young-Soo Yoon ${ }^{2), *}$
}

(Received February 28, 2016, Accepted April 11, 2016, Published online May 3, 2016)

\begin{abstract}
An overall review of the structural behaviors of ultra-high-performance fiber-reinforced concrete (UHPFRC) elements subjected to various loading conditions needs to be conducted to prevent duplicate research and to promote its practical applications. Thus, in this study, the behavior of various UHPFRC structures under different loading conditions, such as flexure, shear, torsion, and high-rate loads (impacts and blasts), were synthetically reviewed. In addition, the bond performance between UHPFRC and reinforcements, which is fundamental information for the structural performance of reinforced concrete structures, was investigated. The most widely used international recommendations for structural design with UHPFRC throughout the world (AFGC-SETRA and JSCE) were specifically introduced in terms of material models and flexural and shear design. Lastly, examples of practical applications of UHPFRC for both architectural and civil structures were examined.
\end{abstract}

Keywords: ultra-high-performance fiber-reinforced concrete, bond performance, structural behavior, design code, application.

\section{Introduction}

Ultra-high-performance fiber-reinforced concrete (UHPFRC), which was developed in the mid-1990s, has attracted much attention from researchers and engineers for practical applications in architectural and civil structures, because of its excellent mechanical performance, i.e., compressive strength is greater than $150 \mathrm{MPa}$ and a design value of tensile strength is $8 \mathrm{MPa}$ (AFGC-SETRA 2002), durability, energy absorption capacity, and fatigue performance (Farhat et al. 2007; Graybeal and Tanesi 2007; Yoo et al. 2014c; Li and Liu 2016). In particular, its very high strength properties result in a significant decrease in the structural weight, i.e., the weight of UHPFRC structures is about $1 / 3$ (or $1 / 2$ ) of the weight of general reinforced concrete (RC) structures at identical external loads (Tam et al. 2012). Consequently, slender structures, which are applicable for long-span bridges, can be fabricated with UHPFRC, leading to low overall construction costs.

In order to apply such a newly developed innovative material to real structures, numerous studies have been carried out in many countries in Europe, North America, and

\footnotetext{
${ }^{1)}$ Department of Architectural Engineering, Hanyang University, Seoul 133-791, Korea.

${ }^{2)}$ School of Civil, Environmental and Architectural Engineering, Korea University, Seoul 136-713, Korea.

*Corresponding Author; E-mail: ysyoon@korea.ac.kr Copyright ( $\odot$ The Author(s) 2016. This article is published with open access at Springerlink.com
}

Asia. Since UHPFRC was first developed by France's research group, the first technical recommendation on UHPFRC for both material properties and structural design was introduced in France in 2002 and was called the AFGCSETRA recommendation (AFGC-SETRA 2002). Thereafter, a state-of-the-art report on UHPFRC covering all material and design aspects was published in Germany in 2003 (DAfStB 2003). Then, in 2004, the Japan Society of Civil Engineers (JSCE) published their own design recommendations for UHPFRC based on Ductal ${ }^{\circledR}$ (Orange et al. 1999), commercial UHPFRC available in the world, (JSCE 2004). Lastly, in recent years, the Korea Concrete Institute (KCI) also developed a design code for UHPFRC (KCI 2012), similar to those in France and Japan, by using K-UHPC, another UHPFRC material developed by Korea Institute of Civil Engineering and Building Technology (Kim et al. 2008).

Due to the superb fiber bridging capacities of UHPFRC at cracked surfaces, leading to a special strain-hardening (or deflection-hardening) response with multiple micro-cracks, many researchers have focused on using it to the structures dominated by flexure, shear, and torsion. Furthermore, UHPFRC has also been considered as one of the promising materials for impact- and blast-resistant structures, because of its enhanced strength and energy absorption capacity, along with strain-hardening cementitious composites containing polymeric fibers (Astarlioglu and Krauthammer 2014; Choi et al. 2014). These properties can help to overcome the brittle failure of plain concrete, which has poor energy absorption capacity for impacts and blasts. Since the structural behaviors of UHPFRC under flexure, shear, and torsion, and when subjected to high-rate loadings, such as impacts and blasts, are highly sensitive to numerous factors, 
i.e., structural shape, loading condition, strain-rate, casting method, reinforcement ratio, etc., it is necessary to synthetically review the scattered studies.

The purpose of this research is to analyze the current state of knowledge of the structural behavior, design techniques, and applications of UHPFRC under various loading conditions. As explained above, the attention of this paper is focused on (1) bond performance between UHPFRC and various reinforcements, which is basic information needed for the design of reinforced structures, (2) structural behavior of UHPFRC under flexure, shear, torsion, and high-rate loading, (3) the most widely used UHPFRC design recommendations in the world, and (4) examples of practical applications in both architectural and civil structures.

\section{Historical Development of UHPFRC}

Roy et al. (1972) and Yudenfreund et al. (1972) first introduced ultra-high-strength cementitious paste with low porosity in the early 1970 s. With special curing methods using heat $\left(250{ }^{\circ} \mathrm{C}\right)$ and pressure $(50 \mathrm{MPa})$, Roy et al. (1972) achieved a cementitious paste with almost zero porosity and a compressive strength of approximately $510 \mathrm{MPa}$. On the other hand, Yudenfreund et al. (1972) obtained a cement paste having a compressive strength of about $240 \mathrm{MPa}$ with normal curing $\left(25^{\circ} \mathrm{C}\right)$ for 180 days. To do this, Yudenfreund et al. (1972) provided a special treatment on-ground clinker, used the low water-to-cement ratio of 0.2, and Blaine surface areas ranging from 6000 to $9000 \mathrm{~cm}^{2} / \mathrm{g}$. After nearly 10 years, Birchall et al. (1981) and Bache (1981) could develop two types of ultra-high-strength paste (or concrete) with very low porosity, such as densified with small particles (DSPs) concrete and macro-defect free (MDF) paste, by developing a pozzolanic admixture and a high-range water-reducing agent. Birchall et al. (1981) achieved the development of the cement pastes with compressive strength over $200 \mathrm{MPa}$ and flexural strengths of 60-70 MPa, by removing macroscopic flaws during material preparation without using fibers or high-pressure compaction. Bache (1981) also successfully developed the concrete that was DSPs and had a compressive strength of 120-270 MPa. The key technique to densely pack the spaces between the cement particles was to use ultra-fine particles and an extremely low water content, with a large quantity of high-range water-reducing agent. In the mid-1990s, Richard and Cheyrezy (1995) first introduced the concept of and mixing sequence for reactive powder concrete (RPC), which was the forerunner of UHPFRC. To obtain a very high strength, the granular size was optimized by the packing density theory, by excluding coarse aggregate and by providing heat $\left(90\right.$ and $400{ }^{\circ} \mathrm{C}$ ) and pressure treatments. In addition, 1.5-3\% (by volume) of straight steel microfibers, with a diameter of $0.15 \mathrm{~mm}$ and a length of $13 \mathrm{~mm}$, were added to achieve high ductility; consequently, the RPC developed by Richard and Cheyrezy (1995) showed compressive strengths of 200-800 MPa and fracture energies up to $40 \mathrm{~kJ} / \mathrm{m}^{2}$.

\section{Performance of Structural UHPFRC Elements}

\subsection{Bond Behavior Between UHPFRC and Reinforcements}

In order to practically apply a newly developed UHPFRC in the structures, bond performance with reinforcements should be examined. Many researchers (Jungwirth and Muttoni 2004; Ahmad Firas et al. 2011; Yoo et al. 2014a, b, 2015a) have investigated the bond behavior of internal steel and fiber-reinforced polymer (FRP) reinforcements with UHPFRC. Jungwirth and Muttoni (2004) carried out pullout test of deformed steel reinforcing bar using a $160 \mathrm{~mm}$ cube. Various bond lengths ranging from 20 to $50 \mathrm{~mm}$ and two different bar diameters of 12 and $20 \mathrm{~mm}$ were adopted. In their study, the average bond strength of steel bars embedded in UHPFRC was found to be $59 \mathrm{MPa}$, approximately 10 times higher than the bond strength of steel bars embedded in ordinary concrete, and the theoretical development length of deformed steel bars in UHPFRC was suggested by $l_{b}=f_{y} d_{b} / 4 \tau_{\max }$, where $f_{y}$ is the yield strength of steel bar, $d_{b}$ is the nominal diameter of steel bar, and $\tau_{\max }$ is the bond strength. Yoo et al. (2014c) examined the effects of fiber content and embedment length on the bond behavior of deformed steel bars embedded in UHPFRC. For this, Yoo et al. (2014c) performed a number of pullout tests by modifying the test method, proposed by RILEM recommendations (RILEM 1994); the $150 \mathrm{~mm}$ cubic specimens with a single bar embedded vertically along the central axis were fabricated and used for testing. The embedment lengths were determined by 1 and 2 times the bar diameter, instead of using $5 d_{b}$, as suggested by the RILEM recommendations. The bond strength was insignificantly affected by the fiber content and embedment length, but it clearly correlated with the compressive strength. The CEB-FIP Model Code (MC90) (CEB-FIP 1993), which defined $\tau_{\max }$ as $2.0 f_{c}^{\prime 0.5}$, substantially underestimated the bond strength of steel bars in UHPFRC because the parameters were suggested based on test data from previous concretes. Thus, Yoo et al. (2014c) proposed modified coefficients for the bond strength of steel bars in UHPFRC, based on a number of test data, as follows (Fig. 1):

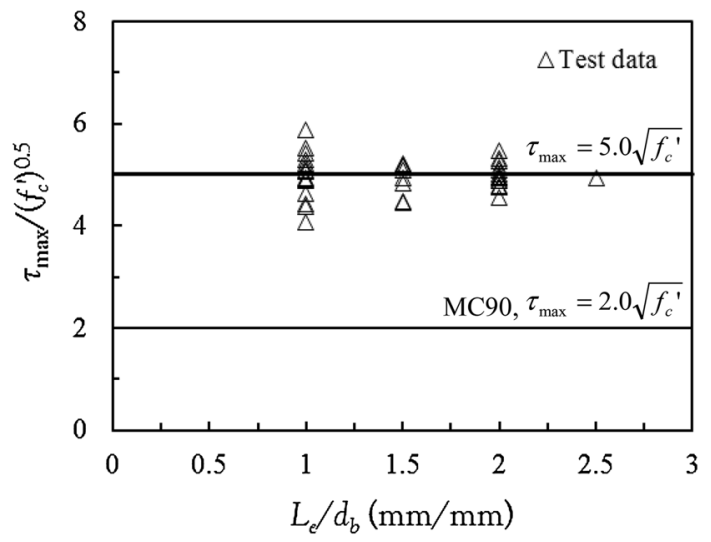

Fig. 1 Normalized bond strengths of deformed steel bars embedded in UHPFRC. 


$$
\tau_{\max }=5.0 \sqrt{f_{c}^{\prime}}
$$

In addition, CMR model (Cosenza et al. 1995), which sets $\tau=\tau_{\max } \times\left(1-\mathrm{e}^{-s / s r}\right)^{\beta}$, was found to be appropriate for simulating the ascending bond stress versus slip behavior of steel bars embedded in UHPFRC, and the parameters were proposed as $\tau_{\max }=5.0 f_{c}^{\prime 0.5}, s_{r}=0.07$, and $\beta=0.8$, where $s_{r}$ and $\beta$ are coefficients based on the curve fitting of test data.

Ahmad Firas et al. (2011) experimentally investigated the bond performance between carbon-fiber-reinforced polymer (CFRP) bars and UHPFRC according to the surface treatment, embedment length, bar diameter, and concrete age. Based on the test data, it was noted that the bond strength was insignificantly affected by the surface treatment of the glass-fiber-reinforced polymer (GFRP) bar; similar bond strengths for smooth bars and sand-coated bars were obtained. On the other hand, a decrease in bond strength was obtained by increasing both bar diameter and embedment length. The ultimate bond strength of CFRP bars in UHPFRC was insignificantly changed by age after 3 days, because it was primarily affected by the shear strength of the connection between the core and the outer layer of the CFRP bars. Ahmad Firas et al. (2011) suggested a development length for sand-coated bars of approximately $40 d_{b}$, and a development length for a smooth bar of longer than $40 d_{b}$. Yoo et al. (2015b) also examined the local bond behavior of GFRP bars embedded in UHPFRC. The average bond strengths of GFRP bars in UHPFRC were found to be from 16.7 to $22.8 \mathrm{MPa}$ for a $d_{b}$ of $12.7 \mathrm{~mm}$, and from 19.3 to $27.5 \mathrm{MPa}$ for a $d_{b}$ of $15.9 \mathrm{~mm}$, which are approximately 73 and $66 \%$ less, respectively, than the bond strengths of deformed steel bars. Similar to the case of CFRP bars in UHPFRC (Ahmad Firas et al. 2011), bond failure was generated by the delamination of the resin and fiber in the bar. Based on a database of 68 pullout test results for GFRP bars in UHPFRC, Yoo et al. (2015b) suggested an equation for the relationship between normalized bond strength and development length by using regression analysis and by assuming no influence of the normalized cover parameter on bond strength, as follows (Fig. 2b):

$$
\frac{u}{\sqrt{f_{c}^{\prime}}}=1.05+0.85 \frac{d_{b}}{L_{e}}
$$

where $u$ is the bond strength $\left(=\tau_{\max }\right), d_{b}$ is the bar diameter, and $L_{e}$ is the embedment length.

The American Concrete Institute (ACI) 440.1R model (ACI 2006) was inappropriate for UHPFRC; it significantly overestimated the test data (normalized bond strength), as shown in Fig. 2a.

Yoo et al. (2015b) also pointed out that the previous model for development length of FRP bar in concrete, suggested by Wambeke and Shield (2006), was not appropriate for UHPFRC; thus, they proposed an expression for the development length of GFRP bars in UHPFRC, which is only valid for the case of pullout failure, as follows:

$$
L_{d, p u l l o u t}=\frac{d_{b} f_{f u}}{3.4 \sqrt{f_{c}^{\prime}}}
$$

where $L_{d \text {,pullout }}$ is the development length and $f_{f u}$ is the ultimate strength of rebar.

Schäfers and Seim (2011) performed experimental and numerical investigations on the bond performance between timber and UHPFRC. The glued-laminated timber was bonded to sandblasted and ground UHPFRC with the "Sikadur 330" epoxy resin. Regardless of the bond length and surface treatment, most of specimens showed failure of the bond in the timber close to the bond-line. Based on the Volkersens theory, Schäfers and Seim (2011) suggested a bond length of $400 \mathrm{~mm}$ for standard test method to evaluate the bond strength of timber-concrete composites and noted that the effect of tensile stresses, orthogonal to the bond-line, can be neglected when the bond length is beyond $300 \mathrm{~mm}$.

\subsection{Flexural Dominated Reinforced UHPFRC Beams, Girders, and Composite Structures}

Due to its excellent post-cracking tensile performance with multiple micro-cracks occurred, UHPFRC has attracted attention from engineers for application in structural elements subjected to bending. Several international recommendations

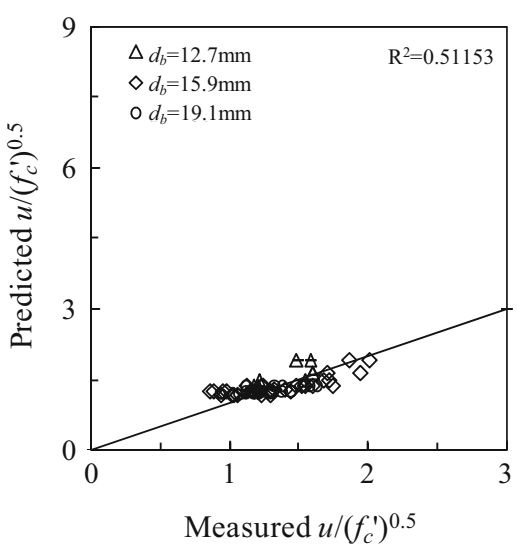

(b)

Fig. 2 Comparison of measured and predicted values of normalized bond strength of GFRP bars in UHPFRC; a ACI 440.1R, b proposed equation (Yoo et al. 2015b). 
(AFGC-SETRA, JSCE, and KCI) from France, Japan, and South Korea (AFGC-SETRA 2002; JSCE 2004; KCI 2012) thus provide stress-strain models for compressive and tensile stress blocks in the cross-section, as well as the detailed process of predicting the ultimate capacity of UHPFRC elements under flexure. Since strain (and stress) distribution in the cross-section varies according to the curvature of a beam, multilayer sectional analysis (Yoo and Yoon 2015) is required to calculate an appropriate neutral axis depth and moment capacity at a certain curvature level.

Yoo and Yoon (2015) first reported test results of a number of reinforced UHPFRC beams to investigate the effects of steel fiber aspect ratio and type on flexural performance. Since a portion of the tensile stress after cracking was resisted by the steel fibers, low reinforcement ratios (percent) of 0.94 and $1.50 \%$ were selected. In order to prevent brittle shear failure, stirrups were conservatively designed based on the specimens made of ultra-high-performance concrete (UHPC) without fibers. From the test results (Fig. 3), the beams made by UHPFRC with $2 \%$ by volume of steel fibers exhibited much higher post-cracking stiffness and ultimate load capacity, compared to those made by UHPC without fiber, called 'NF'. In addition, the use of long straight or twisted steel fibers (S19.5, S30, and T30) led to a higher ductility than the use of short straight steel fibers (S13), which are applied for commercial UHPFRC available in North America (Graybeal 2008), at the identical fiber volume fraction. However, it is very interesting to note that much lower ductility indices were obtained by including steel fibers. This is caused by the fact that due to the very high bond strength between UHPFRC and steel rebar and its crack localization behavior, the steel rebar ruptured at a relatively smaller mid-span deflection, as compared with UHPC beams without fiber. Thus, Yoo and Yoon (2015) concluded that the strain-hardening behavior of UHPFRC was unfavorable to the ductility of reinforced beams.

In order to establish reasonable design codes for UHPFRC, Yang et al. (2010) carried out several four-point flexural tests for UHPFRC beams having reinforcement ratios less than 0.02 . Test variables were the amount of steel rebar and the placement method. From their test results, placing concrete at the ends of the beams yielded better performance than when concrete was placed at the mid-length because of better fiber orientation to the direction of beam length at the maximum moment zone. In addition, they reported that all test beams showed a ductile response with the ductility index ranging from 1.60 to 3.75 and were effective in controlling cracks. However, the meaning of 'ductile response' could be incorrectly delivered to readers because no test results of reinforced UHPC beams without fiber were reported. In accordance with the test results by Yoo and Yoon (2015), reinforced UHPFRC beams exhibited lower ductility indices compared to beams without fiber due to the crack localization behavior, and Dancygier and Berkover (2016) also reported that the inclusion of steel fibers resulted in a decrease of flexural ductility of beams with low conventional reinforcement ratios.

Yang et al. (2011) examined the flexural behavior of largescale prestressed UHPFRC I-beams. They indicated that the high volume content of steel fibers in UHPFRC effectively controlled the increase in crack widths, and led to multiple micro-cracks due to the fiber bridging at crack surfaces. The flexural strength of prestressed UHPFRC I-beams was insignificantly affected by the presence of stirrups. Graybeal (2008) also investigated the flexural behavior of a full-scale prestressed UHPFRC I-girder (AASHTO Type II girder) containing 26 prestressing strands. Based on the experimentally observed behavior, he reported that a UHPFRC Igirder shows larger flexural capacities than that of a conventional concrete girder with similar cross-sectional geometry. In addition, an inversely proportional relationship between crack spacing and maximum tensile strain was experimentally observed, as shown in Fig. 4, and the following equation was suggested:

$$
\varepsilon=450+\frac{2520}{\sqrt{s_{c r}}}+\frac{25,800}{\sqrt{s_{c r}^{2}}} \quad(\text { in } \mathrm{mm})
$$

where $\varepsilon$ is the tensile strain and $s_{c r}$ is the crack spacing.

In recent years, several studies (Ferrier et al. 2015; Yoo et al. 2016) have been carried out to develop a new type of

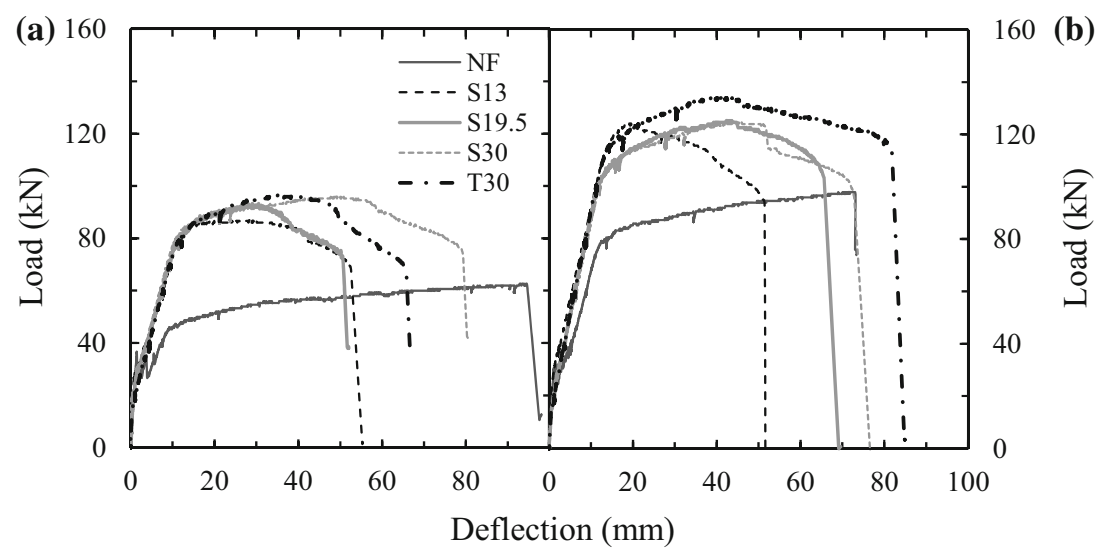

Fig. 3 Load-deflection curves of steel bar-reinforced UHPFRC/UHPC beams; a $\rho=0.94 \%$, b $\rho=1.50 \%$ [NF = UHPC w/o fiber, S13 = UHPFRC w/ straight steel fibers $\left(L_{f} / d_{f}=13 / 0.2 \mathrm{~mm} / \mathrm{mm}\right), S 19.5=$ UHPFRC w/ straight steel fibers $\left(L_{f} /\right.$ $\left.d_{f}=19.5 / 0.2 \mathrm{~mm} / \mathrm{mm}\right), \mathrm{S} 30=$ UHPFRC $\mathrm{w} /$ straight steel fibers $\left(L_{f} / d_{f}=30 / 0.3 \mathrm{~mm} / \mathrm{mm}\right)$, T30 $=$ UHPFRC w/ twisted steel fibers $\left.\left(L_{f} / d_{f}=30 / 0.3 \mathrm{~mm} / \mathrm{mm}\right)\right]$ (Yoo and Yoon 2015). 


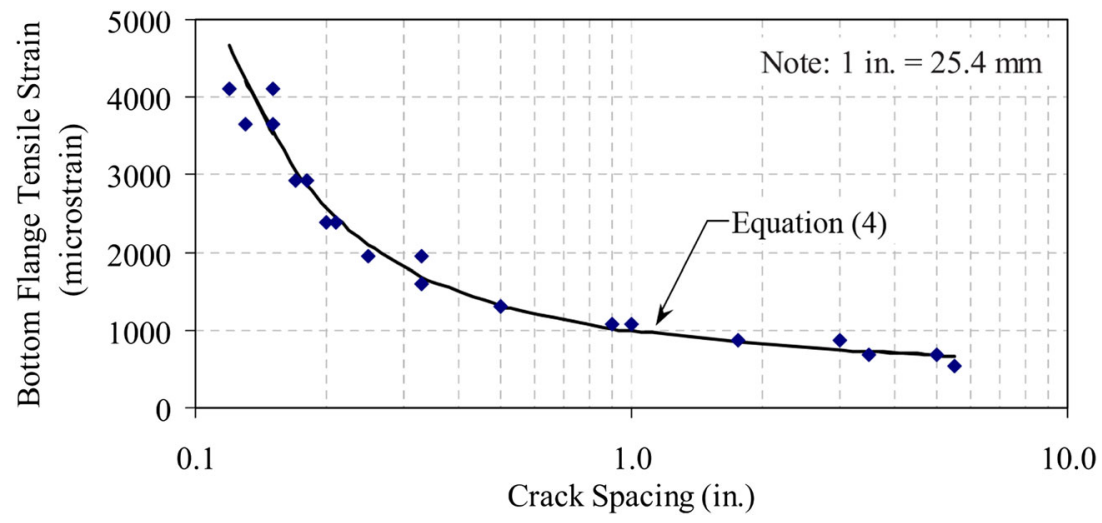

Fig. 4 Tensile strain related to flexural crack spacing of UHPFRC I-girder (Graybeal 2008).

high-performance lightweight beams by applying UHPFRC and FRP rebar. Ferrier et al. (2015) investigated the structural behavior of I-shaped UHPFRC beams reinforced with CFRP and GFRP rebar, according to the rebar axial stiffness ranging from $9 \mathrm{MN}$ to $30 \mathrm{MN}$. Experimental results indicated that the CFRP rebar was effective in increasing the bending stiffness, which results in a lower mid-span deflection, as compared with the case of the GFRP rebar due to the higher elastic modulus of the former. Thus, they concluded that the axial stiffness of the FRP reinforcement is the most influential parameter of bending stiffness of beams. Yoo et al. (2016) also examined the flexural behavior of UHPFRC beams reinforced with GFRP rebar and hybrid reinforcements (steel + GFRP rebar), according to the axial stiffness ranging from 13 to $95.5 \mathrm{MN}$. Hybrid reinforcements were considered in their study because it has been considered as one of the most promising methods to overcome the large service deflection problems of conventional FRP-reinforced concrete beams reported by several researchers (Lau and Pam 2010; Yoon et al. 2011). Due to the strain-hardening characteristics of UHPFRC, all tested beams provided very stiff load versus deflection response even after the formation of cracks (Fig. 5), which is distinctive response with conventional FRP-reinforced concrete beams, and satisfied the service crack width criteria of the
Canadian Standards Association (CAN/CSA) S806 (CAN 2002). Furthermore, the deformability factors suggested by Jaeger et al. (1995) were higher than the lower limit $\left(D_{f}=4\right)$ of CAN/CSA-S6 (CAN 2006) for all test beams. Therefore, it was noted that the use of UHPFRC could be a new solution for solving the major drawbacks limiting the practical application of FRP rebar instead of steel rebar. An increase in the GFRP reinforcement ratio led to an improvement in the flexural performance, such as higher post-cracking stiffness, load carrying capacity, and ductility. However, the application of hybrid reinforcements to UHPFRC nullified the main advantage of using FRP to solve the corrosion problem and showed insignificant improvement in the structural performance. Synthetically, Yoo et al. (2016) recommended the use of GFRP rebar with UHPFRC, rather than the use of hybrid reinforcements.

Ferrier et al. (2009) also examined the flexural behavior of a new type of hybrid beam, made of glued-laminated wood and UHPFRC planks, including steel and FRP rebar. They mention that structural efficiency was obtained by using the hybrid beams, as a consequence of the increased bending stiffness due to the high elastic modulus of UHPFRC planks. In addition, the inclusion of steel and FRP rebar in the lower UHPFRC plank significantly increased the ultimate load capacity of the hybrid beams, as compared with when only

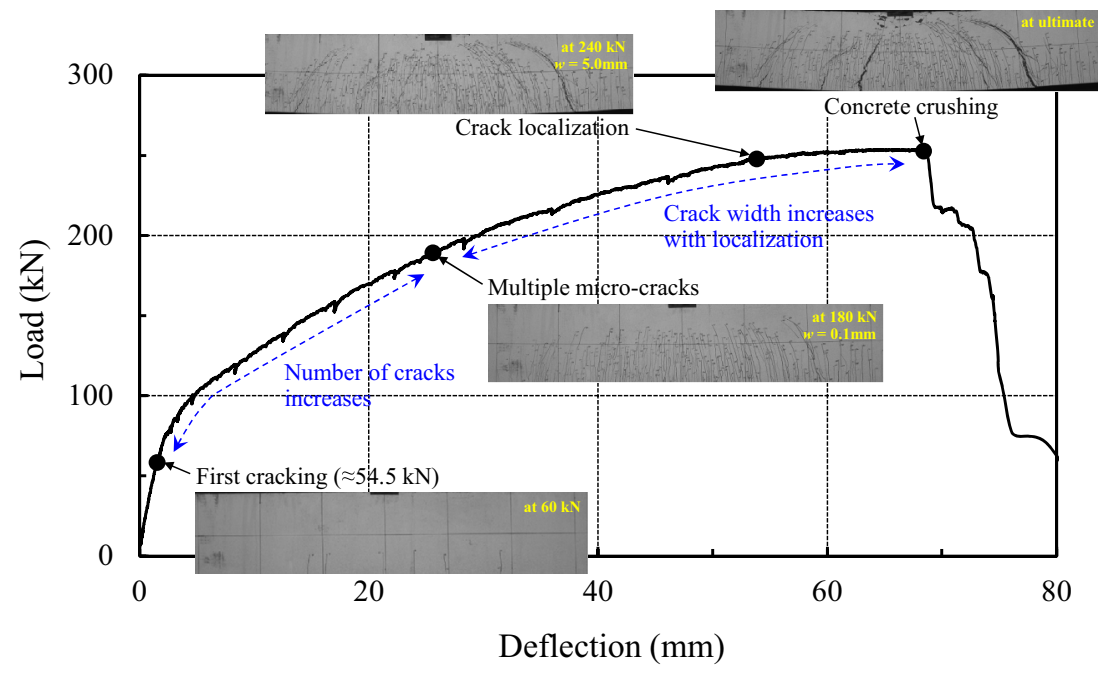

Fig. 5 Typical load-deflection response of GFRP bar-reinforced UHPFRC beam (Yoo et al. 2016). 
pure wood elements were used. These advantages of using hybrid beams lead to the potential for reducing the beam depth or increasing the span length of the beam, compared with conventional timber structures.

To practically apply UHPFRC in real architectural and civil structures, appropriate design technique should be suggested based on the material models. Several international recommendations (AFGC-SETRA 2002; JSCE 2004; KCI 2012) thus provide material models for designing flexural members made of UHPFRC. Based these recommendations, many researchers have already precisely predicted the flexural behaviors of reinforced UHPFRC beams (Yang et al. 2010; Yang et al. 2011; Ferrier et al. 2015; Yoo and Yoon 2015; Yoo et al. 2016). In particular, the UHPFRC beams without stirrups were well predicted by AFGCSETRA recommendations without consideration of fiber orientation coefficient $(K=1)$ (Yang et al. 2011; Yoo et al. 2016) because the fiber alignment in the direction of beam length was insignificantly disturbed by the internal rebars. However, Yoo and Yoon (2015) recently reported that the fiber orientation coefficient that is proposed by the AFGCSETRA recommendations (i.e., $K=1.25$ ), should be considered for simulating the flexural behavior of reinforced UHPFRC beams with stirrups, since the fiber orientation was clearly disturbed by the stirrups (Fig. 6). In the case of FRPreinforced concrete elements, it is well known that the service deflection prediction is the most important parameter for designing such structures, because of the larger service deflection than that of beams reinforced with steel rebar. Ferrier et al. (2015) and Yoo et al. (2016) successfully predicted the load versus deflection curves of FRP-bar-reinforced UHPFRC beams by sectional analysis, in which they considered compressive and tensile stress blocks in the cross-section, similar to the method used for the above steelbar-reinforced beams. Yoo and Banthia (2015) also accurately predicted the service deflection of UHPFRC beams reinforced with GFRP rebar and hybrid reinforcements (steel + GFRP rebar), based on a micromechanics-based finite element (FE) analysis; the average ratios of the serviceability deflections from predictions and experiments were found to be 0.91 with a standard deviation of 0.07 .

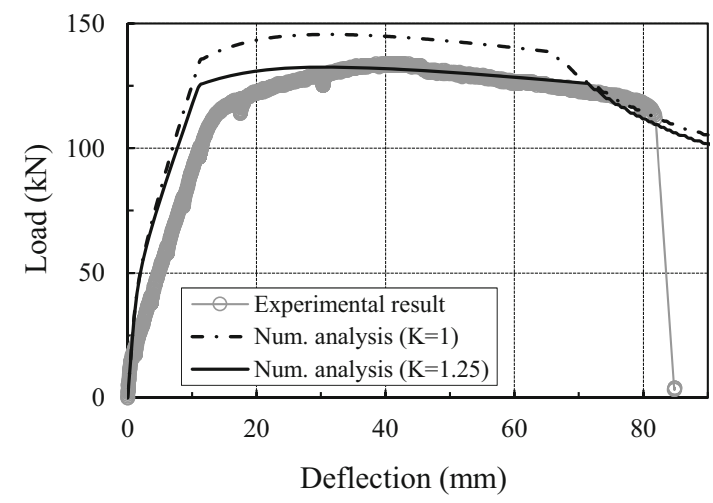

Fig. 6 Comparison of experimental and numerical results for steel bar-reinforced UHPFRC beams with stirrups according to fiber orientation coefficient (Yoo and Yoon 2015).

\subsection{Shear Resistance of Structural UHPFRC Beams, Girders, and Bridge Decks}

Baby et al. (2013b) carried out shear tests of eleven 3-m long UHPFRC I-shaped girders with various shear reinforcements (stirrups and/or steel fibers, or neither) combined with longitudinal prestressing or passive steel bars. To examine the actual fiber orientation effect on the shear performance, the three-point flexural tests were performed by using notched prism specimens extracted from both of the undamaged ends of I-girders at different inclination angles. Test results, as shown in Fig. 7, clearly indicated that the fiber orientation significantly influenced the mechanical (flexural) performance; thus, they noted that the actual fiber orientation needs to be taken into account for shear design, as recommended by AFGC-SETRA recommendations (AFGC-SETRA 2002). By including $2.5 \%$ steel fibers, an almost $250 \%$ increase in shear strength was observed (Baby et al. 2013c). The stirrups yielded first, while localization of the shear crack took place significantly later, as shown in Fig. 8. Thus, crack localization is primarily influenced by the strain capacity of the UHPFRC, and the contributions of the fiber bridging and the stirrups up to their yield strength seem to be effective only when the tensile strain capacity of the UHPFRC is much higher than the yield strain of the stirrups. In their study (Baby et al. 2013c), the AFGCSETRA recommendations were conservative for the shearcracking strength, but reasonable for the ultimate shear strength prediction of UHPFRC I-girders. Baby et al. (2013a) also examined the feasibility of applying the modified compression field theory for the shear capacity of reinforced or prestressed UHPFRC beams. Based on their analytical results, the modified compression field theory was determined to be applicable for predicting the shear behavior with an effective estimation of the reorientation of the compressive struts with an increase in the load.

Voo et al. (2010) investigated the shear strength of prestressed UHPFRC I-beams without stirrups, according to the shear span-to-depth ratio $(a / d)$ and the type of steel fibers. They indicated that a higher shear strength was obtained by using a higher fiber volume content and a lower $a / d$. The theory of the plastic shear variable engagement model presented a good basis for their shear design and a good

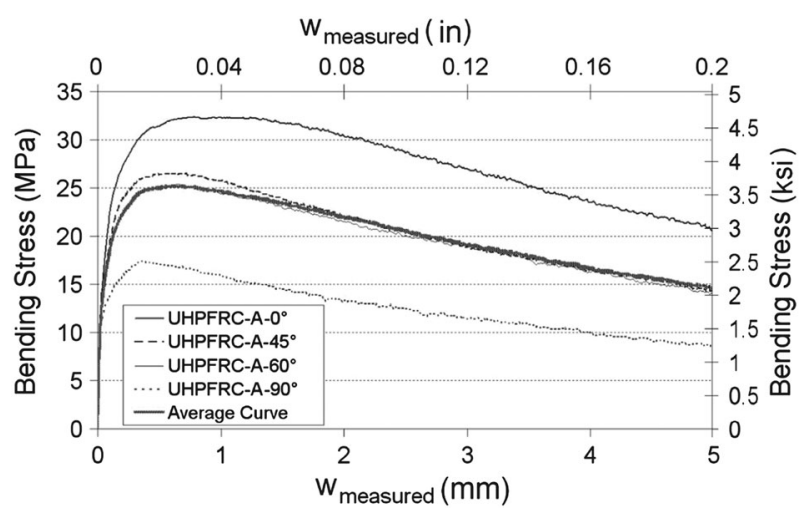

Fig. 7 Three-point bending test results of prisms extracted from l-girders at different inclinations (Baby et al. 2013b). 


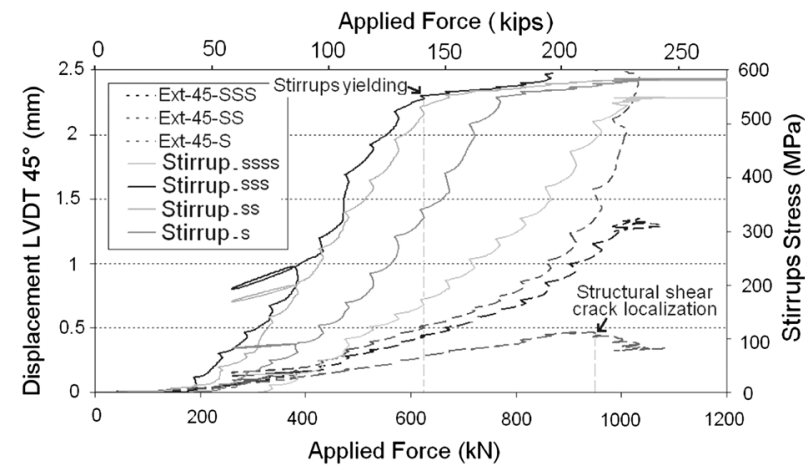

Fig. 8 Evolution during tests of stresses inside stirrups and displacements measured by LVDTs attached at $45^{\circ}$ in the web (Baby et al. 2013b).

relationship to the experimental results; the ratio of shear strengths obtained from experiment and theory was found to be 0.92 , with a coefficient of variation of 0.12 . In addition, Bertram and Hegger (2012), Yang et al. (2012), and Tadepalli et al. (2015) mentioned that the shear strength increased with an increase in the fiber content and a decrease in the a/d ratio. For instance, the inclusion of $2.5 \%$ steel fibers led to a $177 \%$ higher ultimate load than that without fiber, and by changing the $a / d$ ratio from 3.5 to 4.4 , the shear capacity was reduced by $10 \%$ (Bertram and Hegger 2012). Bertram and Hegger (2012) also noted that the size effect on shear strength was more substantially affected by the beam height as compared with the web thickness, and that about $12-14 \%$ higher shear capacity was obtained when the effective prestressing force increased by $20 \%$. By comparing the test results with computed values, Yang et al. (2012) noticed that the predictions using the AFGC-SETRA and JSCE recommendations provided accurate estimates of the shear strength of UHPFRC I-beams (Fig. 9).

In order to replace the open-grid steel decks from moveable bridges, which have several drawbacks, such as poor rideability, high noise levels, susceptibility to fatigue damage, and high maintenance costs, Saleem et al. (2011) examined the structural performance of lightweight UHPFRC bridge decks reinforced with high-strength steel rebar. They properly designed and proposed UHPFRC waffle decks to satisfy the strength, serviceability, and selfweight requirements for moveable bridges. The governing

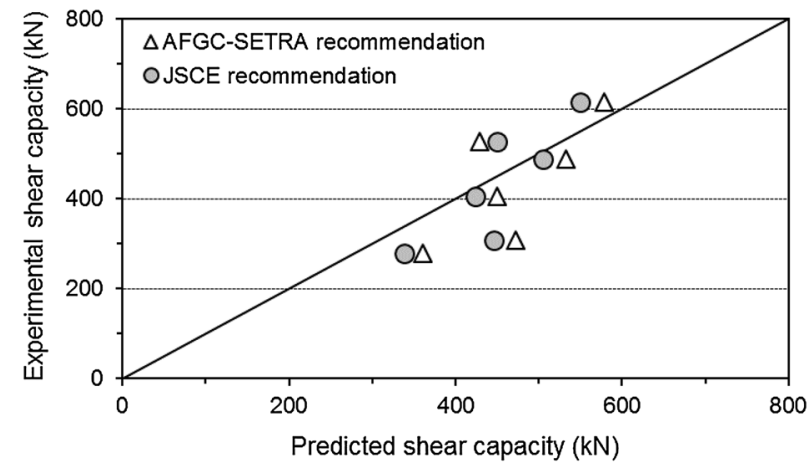

Fig. 9 Comparison of experimental and predicted shear capacities (Yang et al. 2012). failure mode was shear, and in the multi-unit decks, shear failure was followed by punching shear failure at close to the ultimate state. However, the shear failure was less abrupt and catastrophic as compared with the commonly seen shear failure mode. Thus, Xia et al. (2011) recommended the ductile shear failure with higher post-cracking shear resistance of UHPFRC beams containing high-strength steel rebar as an acceptable failure mode, rather than including transverse reinforcements, because of their economic problems. The use of $180^{\circ}$ hooks at both ends of the steel rebar, recommended by ACI 318 (ACI 2014), was also effective in avoiding bond failure, compared with specimens without end anchorage. Based on a thorough analysis of the experimental results, Saleem et al. (2011) noted that although the proposed UHPFRC waffle deck system exhibits shear failure mode, it has great potential to serve as an alternative to opengrid steel decks, which are conventionally used for lightweight or moveable bridges.

\subsection{Torsional Behavior of Structural UHPFRC Beams and Girders}

Empelmann and Oettel (2012) examined the effect of adding steel fibers ( $v_{f}$ of 1.5 and $2.5 \%$ ) on the torsional behavior of UHPFRC box girders. They experimentally observed that the inclusion of steel fibers led to a better cracking performance such as smaller crack widths and multitudinous cracks, higher ultimate and cracking torque, and improved torsional stiffness. Interestingly, the angle of the diagonal cracks was found to be approximately $45^{\circ}$ for all test series, regardless of the steel fiber contents. Yang et al. (2013) also investigated the torsional behavior of UHPFRC beams reinforced with mild steel rebars. In order to estimate the effects of steel fiber content and transverse and longitudinal rebar ratios, thirteen UHPFRC beams were fabricated and tested. Based on their test results (Yang et al. 2013), an improvement in the initial cracking and ultimate torque were obtained by increasing the fiber volume fractions (Fig. 10a), which is consistent with the findings from Empelmann and Oettel (2012). Moreover, higher ultimate torque was found with increases in the ratio of stirrups with longitudinal rebar (Figs. 10b and 11c). In addition, the torsional stiffness after initial cracking was also improved by increasing the ratio of stirrups, as shown in Fig. 10b. In contrast to Empelmann and Oettel's findings, Yang et al. (2013) reported that the angle of the diagonal compressive stress ranged from $27^{\circ}$ to $53^{\circ}$, and was affected by the number of stirrups and longitudinal rebar. For example, the angle of localized diagonal cracks increased with an increase in the number of stirrups, as illustrated in Fig. 11. Fehling and Ismail (2012) also reported similar test results for the torsional behavior of UHPFRC elements. They specifically said that the inclusion of steel fibers was effective in improving the torsional performance, such as cracking and ultimate torsional capacities, torsional ductility, post-cracking stiffness, and toughness. The use of longitudinal reinforcements and stirrups also obviously improved the torsional performance. 


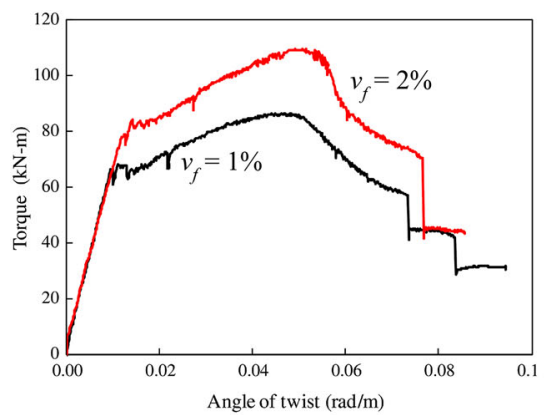

(a)

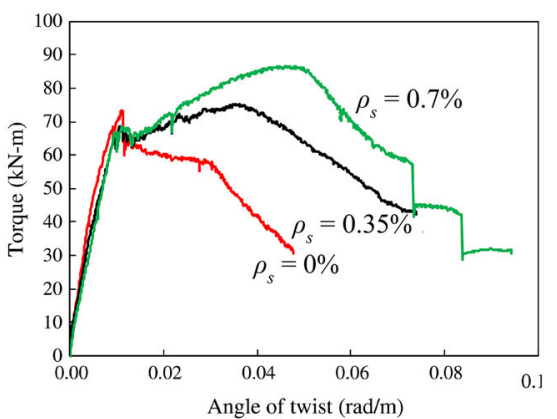

(b)

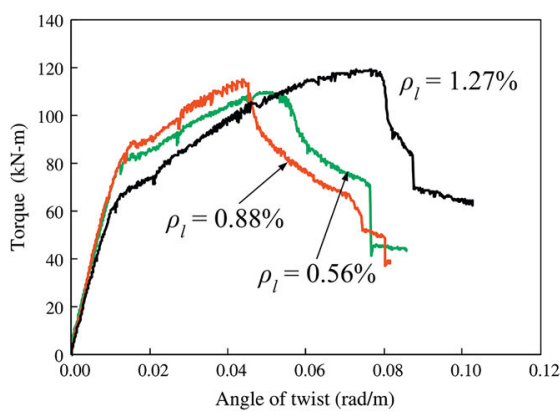

(c)

Fig. 10 Torque-twist curves of UHPFRC beams $\left(v_{f}=\right.$ volume fraction of steel fiber, $\rho_{s}=$ transverse reinforcement ratio, $\rho_{l}=$ longitudinal reinforcement ratio); a effect of steel fiber content, $\mathbf{b}$ effect of transverse reinforcement ratio, $\mathbf{c}$ effect of longitudinal reinforcement ratio (Yang et al. 2013).

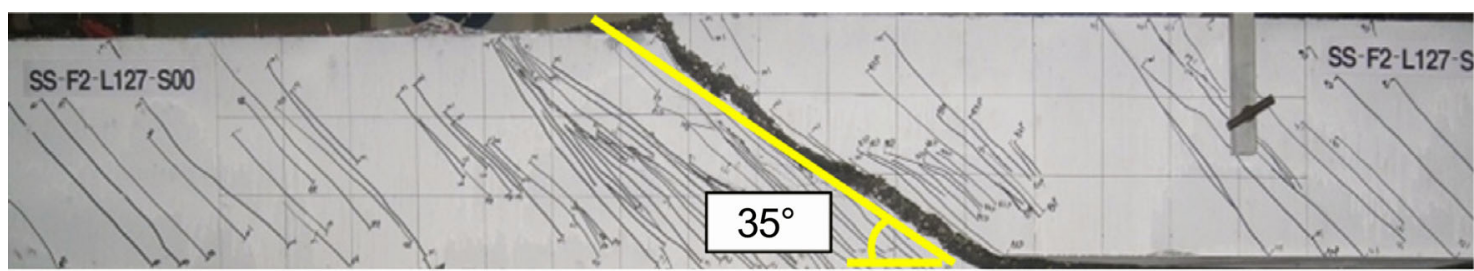

(a) $v_{f}=2 \%, \rho_{l}=1.27 \%$, and $\rho_{s}=0 \%$

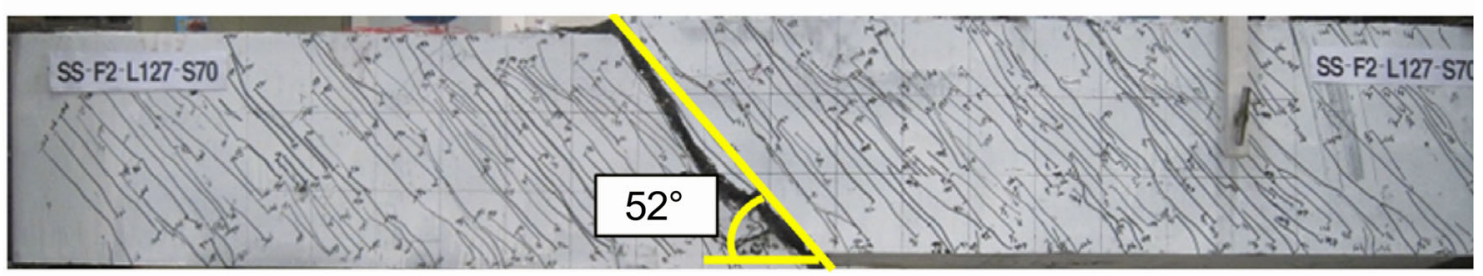

(b) $v_{f}=2 \%, \rho_{l}=1.27 \%$, and $\rho_{s}=0.7 \%$

Fig. 11 Angle of localized diagonal cracks $\left(v_{f}=\right.$ volume fraction of steel fiber, $\rho_{s}=$ transverse reinforcement ratio, $\rho_{l}=$ longitudinal reinforcement ratio) (Yang et al. 2013).

\subsection{Performance of Structural UHPFRC Beams, Slabs, and Columns Under Extreme Loadings}

Fujikake et al. (2006a) and Yoo et al. (2015a, c) examined the impact resistance of reinforced or prestressed UHPFRC beams by testing a number of specimens using a drop-weight impact test machine. In their studies (Fujikake et al. 2006a), an increase in the maximum deflection of UHPFRC beams was observed by increasing the drop height while maintaining the weight of the hammer, owing to the increase of kinetic energy. The initial stiffness in the UHPFRC beams was insignificantly affected by the impact damage because of the excellent fiber bridging capacities after matrix cracking, and the residual load-deflection (or moment-curvature) curves, shifted based on the maximum deflection by impact, exhibited quite similar behaviors with those of the virgin specimens without impact damage. Hence, Fujikake et al. (2006a) mentioned that the maximum deflection response can be used as the most rational index for estimating the overall flexural damage of reinforced UHPFRC beams. Yoo et al. (2015a) reported that better impact resistance, i.e., lower maximum and residual deflections and higher deflection recovery, was obtained by increasing the amount of longitudinal steel rebars, and the maximum and residual deflections of reinforced UHPFRC beams decreased significantly by adding $2 \%$ (by volume) of steel fibers, leading to a change in the damage level from severe to moderate, whereas slight decreases in the maximum and residual deflections were found by increasing the fiber length at identical volume fractions (Yoo et al. 2015c). A higher ultimate load capacity was also obtained for the beams under impact loading, compared to those under quasi-static loading, and the residual load capacity after impact damage improved by including $2 \%$ steel fibers and using the longer steel fibers. Fujikake et al. (2006a) and Yoo et al. (2015a) successfully predicted the mid-span deflection versus the time response of structural UHPFRC beams by using the sectional analysis and single- (or multi-) degree-of-freedom model. Improved mechanical compressive and tensile strengths according to the strain-rate were considered in the analysis by using the equations for the dynamic increase factor (DIF) of the UHPFRC, as suggested by Fujikake et al. (2006b, 2008).

Aoude et al. (2015) investigated the blast resistance of full-scale self-consolidating concrete (SCC) and UHPFRC columns under various blast-impulse combinations based on a shock-tube instrumentation. They verified that the steel 
bar-reinforced UHPFRC columns showed substantially higher blast resistance than the reinforced SCC columns in terms of reducing the maximum and residual deflections, enhancing damage tolerance, and eliminating secondary blast fragments. Based on the single-degree-of-freedom (SDOF) model and lumped inelasticity approach, Aoude et al. (2015) predicted the inelastic deflection-time histories. From the numerical results, several important findings were obtained as follows; (1) since the numerical predictions are sensitive to the choice of DIF, as given in Fig. 12a, further study needs to be done to develop the strain-rate models for using in the blast analysis of UHPFRC columns, and (2) the plastic hinge length $\left(L_{p}\right)$ seems to be reduced in UHPFRC columns from $L_{p}=d$ (column effective depth), which has been used for the analysis in conventional reinforced concrete columns, as shown in Fig. 12b. Astarlioglu and Krauthammer (2014) numerically simulated the response of normal-strength concrete (NC) and UHPFRC columns subjected to blast loadings based on SDOF models using the dynamic structural analysis suite (DSAS) and reported that the UHPFRC columns presented lower mid-span displacement and sustained more than four times the impulse as compared with the NC columns.

$\mathrm{Wu}$ et al. (2009) carried out a series of blast tests of NC and UHPFRC slabs $\mathrm{w} /$ and w/o reinforcements to examine their blast resistance. When the similar blast loads were applied, the UHPFRC slabs without reinforcement exhibited less damage than the NC slabs with reinforcements, and thus, they noticed that the application of UHPFRC is effective in blast design. The UHPFRC slab with passive reinforcements was superior to all other slab specimens, and the strengthening of NC slabs with external FRP plates in the compressive zone was efficient in improving the blast resistance. Yi et al. (2012) examined the blast resistance of the reinforced slabs made of $\mathrm{NC}$, ultra-high-strength concrete (UHSC), and RPC, which is identical to UHPFRC. By analyzing the crack patterns and maximum and residual deflections, they indicated that RPC has the best blast-resistant capacity, followed by UHSC and then NC. For example, the maximum deflections of NC, UHSC, and RPC slabs from 15.88 ANFO charge were found to be 18.57 ,

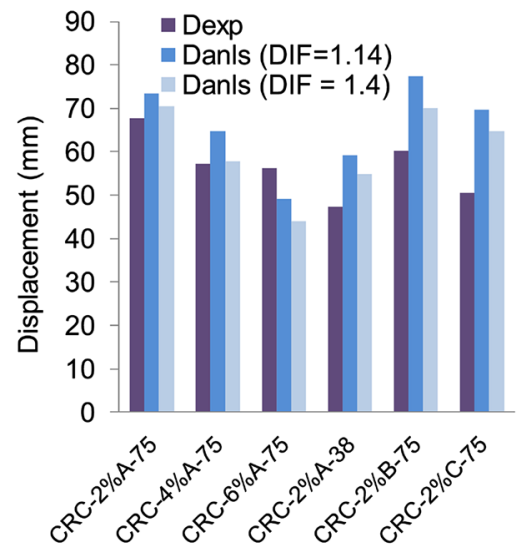

(a)
15.14, and $13.09 \mathrm{~mm}$, respectively. Mao et al. (2014) investigated the capability of modeling the impact behavior of UHPFRC slabs using the commercial explicit FE program, LS-DYNA (2007). Through FE analysis, they also studied the effects of steel fibers and rebar on the blast resistance of UHPFRC slabs. Importantly, they observed that the $\mathrm{K} \& \mathrm{C}$ model (mostly used for simulating the blast behavior of concrete structures) with automatically generated parameters provided a much better ductile response than the actual behavior, and thus, a modified parameter $b_{2}$ from 1.35 to -2 should be applied for UHPFRC. After verifying the numerical modeling with test data, a parametric study was carried out, and some useful results were obtained: (1) the additional use of steel fibers and rebar provide similar influence in the form of extra resistance to the UHPFRC panel under far field blast loading, and (2) under near field blast loading, the resistance of the UHPFRC panels increased substantially with steel rebar, as shown in Fig. 13.

\section{Structural Design of UHPFRC Based on AFGC-SETRA and JSCE Recommendations}

\subsection{AFGC-SETRA Recommendations \\ 4.1.1 Material Models}

In AFGC-SETRA recommendations, UHPFRC is referred to as a cementitious material with a compressive strength in excess of $150 \mathrm{MPa}$, possibly obtaining $250 \mathrm{MPa}$, and including steel (or polymer) fibers to provide a ductile tensile behavior. The parameters of the design strength were suggested based on the mechanical test results of Ductal ${ }^{\circledR}$ (Orange et al. 1999), as follows: $f_{c k}=150-250 \mathrm{MPa}$, $f_{t j}=8 \mathrm{MPa}$, and $E_{c}=55 \mathrm{GPa}$, where $f_{c k}$ is the compressive strength, $f_{t j}$ is the post-cracking direct tensile strength, and $E_{c}$ is the elastic modulus. A partial safety factor $\gamma_{b f}$ is also introduced, with $\gamma_{b f}=1.3$ in the case of fundamental combinations and $\gamma_{b f}=1.05$ in the case of accident combinations. To consider the fiber orientation effect on the tensile behavior, three different fiber orientation coefficients were

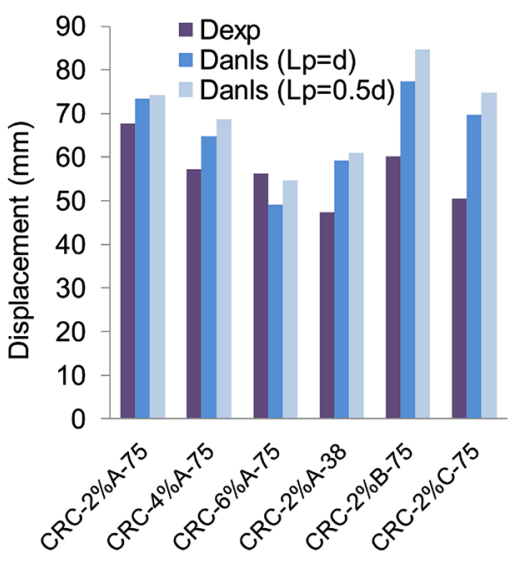

(b)

Fig. 12 Displacement predictions from SDOF analysis for UHPFRC columns (Note CRC means UHPFRC); a DIF = 1.14 vs. 1.4 , b hinge length, $L_{p}=d$ vs. $0.5 d$ (Aoude et al. 2015). 


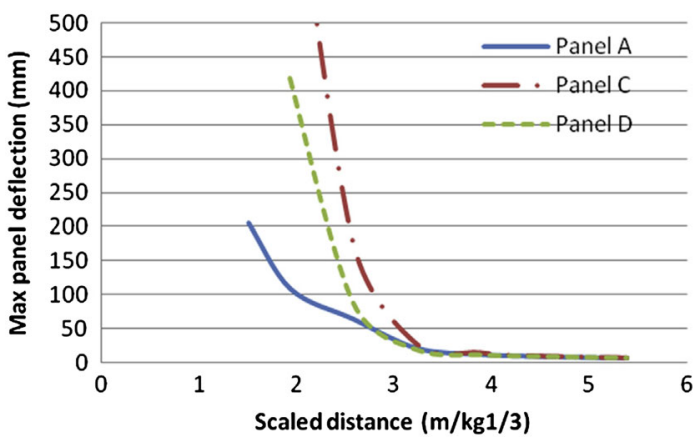

Fig. 13 Variation of maximum panel deflection with scaled distance from three UHPFRC panels (Panel $A$ has $2 \%$ of $13 \mathrm{~mm}$ long steel fibers with $3.4 \%$ steel rebars, Panel $C$ has $2 \%$ of $13 \mathrm{~mm}$ long steel fibers with $0.3 \%$ steel rebars, and Panel $D$ has $2 \%$ of $13 \mathrm{~mm}$ and $2 \%$ of $25 \mathrm{~mm}$ long steel fibers with $0.3 \%$ steel rebars) (Mao et al. 2014).

suggested, as follows: $K=1$ for placement methods validated from test results of a representative model of actual structure, $K=1.25$ for all loading other than local effects, and $K=1.75$ for local effects.

In the case of compressive model, a bilinear stress-strain model can be used, as shown in Fig. 14, with the design strength and strain parameters- $\sigma_{b c u}=0.85 f_{c k} / \theta \gamma_{\mathrm{b}}$ and $\varepsilon_{u}=0.003$.

The tensile stress-crack opening displacement $(\sigma-$ w) model is recommended to be first derived based on an inverse analysis. To apply the $\sigma-w$ model into the tensile stress block in the cross-section, it needs to be transformed to the tensile stress-strain $(\sigma-\varepsilon)$ model by using the characteristic length, $l_{c}$, which is $l_{c}=2 / 3 \times h$ for the case of rectangular or T-beams, where $h$ is the beam height.

To obtain the tensile $\sigma-\varepsilon$ model, the elastic tensile strain and strains at crack widths of $0.3 \mathrm{~mm}$ and $1 \%$ of beam height need to be calculated based on the following equations:

$$
\varepsilon_{e}=\frac{f_{t j}}{E_{c}}
$$

$$
\begin{aligned}
& \varepsilon_{0.3}=\frac{w_{0.3}}{l_{c}}+\frac{f_{t j}}{\gamma_{b f} E_{c}} \\
& \varepsilon_{1 \%}=\frac{w_{1 \%}}{l_{c}}+\frac{f_{t j}}{\gamma_{b f} E_{c}}
\end{aligned}
$$

where $\varepsilon_{e}$ is the elastic strain, $w_{0.3}$ is the crack width of $0.3 \mathrm{~mm}, \varepsilon_{0.3}$ is the strain at crack width of $0.3 \mathrm{~mm}, w_{1 \%}$ is the crack width corresponding to $0.01 H$ ( $H$ is the specimen height), and $\varepsilon_{1 \%}$ is the strain at crack width corresponding to $0.01 H$.

The ultimate tensile strain is expressed by $\varepsilon_{\lim }=L_{f} / 4 l_{c}$, where $\varepsilon_{\lim }$ is the ultimate tensile strain and $L_{f}$ is the fiber length.

The stresses at two different characteristic points (at $w_{0.3}$ and $\left.w_{1 \%}\right)$ are expressed as follows:

$$
\begin{gathered}
f_{b t}=\frac{f\left(w_{0.3}\right)}{K \gamma_{b f}} \\
f_{1 \%}=\frac{f\left(w_{1 \%}\right)}{K \gamma_{b f}}
\end{gathered}
$$

where $f_{b t}$ is the stress at a crack width of $0.3 \mathrm{~mm}$ and $f_{1 \%}$ is the stress at a crack width corresponding to $0.01 \mathrm{H}$.

The completed material models under compression and tension are given in Fig. 14. Based on the capacity of tensile resistance with crack opening displacement, the AFGCSETRA recommendations classify the tensile response by two different laws: (1) the strain-softening law $\left(f_{t j}>f_{b t}\right)$ and (2) the strain-hardening law $\left(f_{t j}<f_{b t}\right)$, as shown in Fig. 14.

Other important material properties of UHPFRC with heat treatment are given by AFGC-SETRA recommendations, as follows:

- Poisson's ratio: 0.2.

- Thermal expansion coefficient $\left(\times 10^{-6} /{ }^{\circ} \mathrm{C}\right)$ : 11.0 .

- Long-term creep coefficient: 0.2.

- Total (autogenous) shrinkage: $550 \times 10^{-6}$.

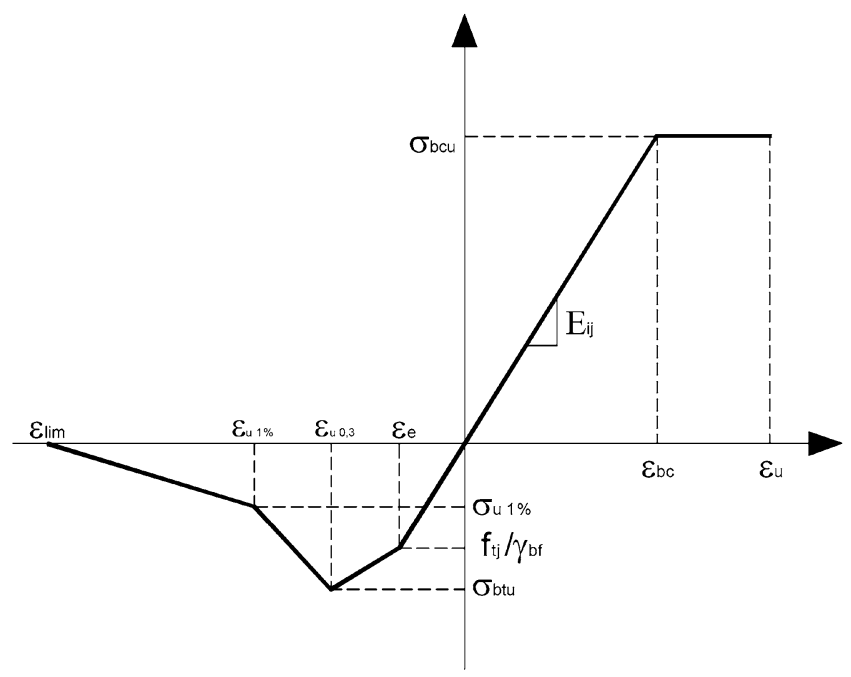

(a)

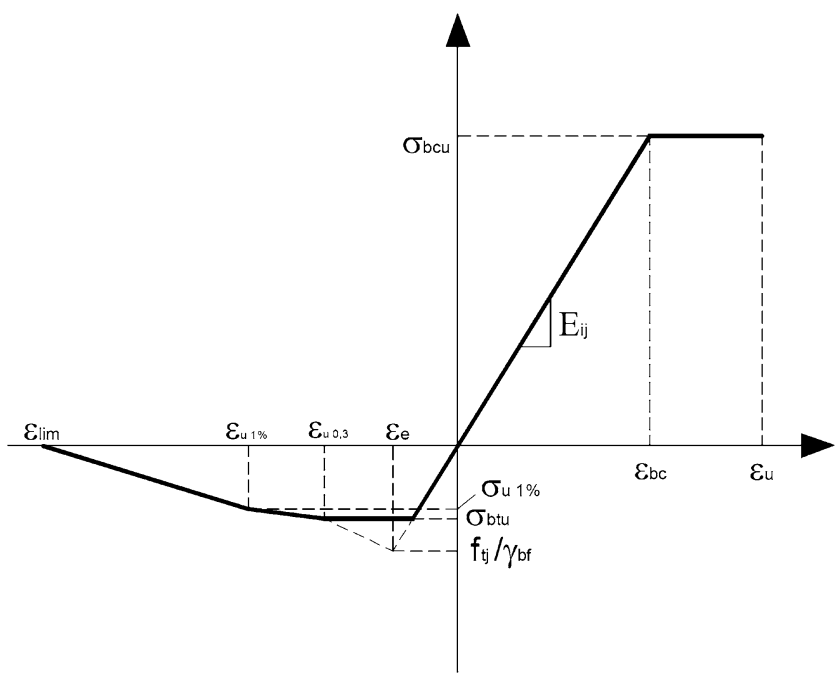

(b)

Fig. 14 Material models [AFGC-SETRA recommendations (AFGC-SETRA 2002)]; a strain-hardening, b strain-softening. 


\subsubsection{Flexural Design}

A chapter for the flexural design of UHPFRC structures is not included in the AFGC-SETRA recommendations. However, based on the suggested material models in Fig. 14, the design of a UHPFRC element subjected to bending can be performed by using the sectional analysis (Fujikake et al. 2006a; Yang et al. 2011; Ferrier et al. 2015; Yoo and Yoon 2015; Yoo et al. 2016). A schematic description of a multi-layered cross-section with strain and stress distributions and an algorithm for sectional analysis are shown in Fig. 15 (Yoo and Yoon 2015). The crosssection of the elements is first divided into a number of layers along the height. After that, the compressive and tensile stresses at each layer can be calculated by assuming that the plane section remains a plane at a given curvature. Then, the neutral axis depth can be calculated from the force equilibrium condition. Lastly, the moment is calculated. The calculation was repeated until the ultimate strain of the steel rebar was reached.

\subsubsection{Shear Design}

Since the steel fibers can resist a portion of the stress at shear cracks, they mentioned that stirrups may be used, but the shear strength given by the fibers may make it possible to dispense with the stirrups. The ultimate shear strength $V_{u}$ is given by:

$$
V_{u}=V_{R b}+V_{a}+V_{f}
$$

where $V_{R b}$ is the term for the participation of the concrete, $V_{a}$ is the term for the participation of the reinforcement, and $V_{f}$ is the term for the participation of the fibers.

The shear strength by reinforcement $V_{a}$ is given by:

$$
V_{a}=0.9 d \frac{A_{t}}{s_{t}} \frac{f_{e}}{\gamma_{s}}(\sin \alpha+\cos \alpha)
$$

where $d$ is the effective depth, $A_{t}$ is the area of the stirrups, $s_{t}$ is the spacing of the stirrups, $f_{e}$ is the stress in the stirrups, $\gamma_{s}$ is the partial safety factor, and $\alpha$ is the inclination angle of the stirrups.

$V_{R b}$ is expressed by two equations for reinforced and prestressed concrete, as follow:

$$
\begin{aligned}
& V_{R b}=\frac{1}{\gamma_{E}} \frac{0.21}{\gamma_{b}} k \sqrt{f_{c k}} b_{0} d \quad \text { (for reinforced concrete) } \\
& V_{R b}=\frac{1}{\gamma_{E}} \frac{0.24}{\gamma_{b}} \sqrt{f_{c k}} b_{0} z \quad \text { (for prestressed concrete) }
\end{aligned}
$$

where $\gamma_{E}$ is the safety coefficient such that: $\gamma_{E} \times \gamma_{b}=1.5$, $b_{0}$ is the element width, $\sigma_{m}$ is the mean stress in the total section of concrete under the normal design force, $k=1+3 \sigma_{c m} / f_{t j}$ for compression, $k=1-0.7 \sigma_{t m} / f_{t j}$ for tension, and $z$ is the distance from the top fiber to the center of prestressing strand.

Lastly, the shear strength of the fibers is calculated by using the following equation:

$$
\begin{aligned}
& V_{f}=\frac{S \sigma_{p}}{\gamma_{b f} \tan \beta_{u}} \\
& \sigma_{p}=\frac{1}{K} \frac{1}{w_{\lim }} \int_{0}^{w_{\lim }} \sigma(w) d w \\
& \text { with } w_{\text {lim }}=\max \left(w_{u} ; 0.3 \mathrm{~mm}\right) \text { and } w_{u}=l_{c} \varepsilon_{u}
\end{aligned}
$$

where $S$ is the area of the fiber effect $\left(S=0.9 b_{0} d\right.$ or $b_{0} d$ for rectangular or T-sections, and $S=0.8(0.9 d)^{2}$ or $0.8 z^{2}$ for circular sections), $\beta_{u}$ is the inclination angle between a diagonal crack and the longitudinal direction of the beam, $K$ is the orientation coefficient for general effects, $\sigma(w)$ is the experimental characteristic postcracking stress for a crack width of $w$, and $w_{u}$ is the ultimate crack width.

\subsection{JSCE Recommendations \\ 4.2.1 Material Models}

In JSCE recommendations, UHPFRC is defined as the concrete with $f_{c}^{\prime} \geq 150 \mathrm{MPa}, f_{c r k} \geq 4 \mathrm{MPa}$, and $f_{t k} \geq 5$ $\mathrm{MPa}$, where $f_{c}^{\prime}$ is the compressive strength, $f_{c r k}$ is the cracking strength, and $f_{t k}$ is the tensile stress at crack width of $0.5 \mathrm{~mm}$. JSCE recommendations were proposed based on Ductal $^{\circledR}$ (Orange et al. 1999), which is commercially available UHPFRC with heat treatment and 2 vol.\% of steel fibers having $d_{f}=0.2 \mathrm{~mm}$ and $L_{f}=15 \mathrm{~mm}$, and provided the strength properties used for structural design as follows; $f_{c}^{\prime}=180 \mathrm{MPa}, f_{c r k}=8 \mathrm{MPa}, f_{t k}=8.8 \mathrm{MPa}$, and $E_{c}=50$ GPa. Importantly, they suggested a bilinear stress-strain curve for compression (Fig. 16a) and a bilinear tensionsoftening curve (TSC) with $f_{t k}=8.8 \mathrm{MPa}, w_{1 k}=0.5 \mathrm{~mm}$, and $w_{2 k}=4.3 \mathrm{~mm}$ for tension (Fig. 16b). In order to obtain the structural safety, $\gamma_{c}=1.3$ was proposed for the partial safety factor. To take into account the suggested TSC for tensile stress block in the cross-section, the crack opening displacement should be transformed to a strain by using the equivalent specific length, $L_{e q}$, as follows

$$
L_{e q}=0.8 h\left[1-\frac{1}{\left(1.05+6 h / l_{c h}\right)^{4}}\right]
$$

where $h$ is the overall depth of beam, $l_{c h}$ is the characteristic length $\left(=G_{F} E_{c} / f_{t k}^{2}\right)$, and $G_{F}$ is the fracture energy.

By using the equivalent specific length, the tensile stressstrain model is obtained by the following equations, based on the TSC:

$$
\begin{aligned}
& \varepsilon_{c r}=\frac{f_{t k}}{\gamma_{c} E_{c}} \\
& \varepsilon_{1}=\varepsilon_{c r}+\frac{w_{1 k}}{L_{e q}} \\
& \varepsilon_{2}=\frac{w_{2 k}}{L_{e q}}
\end{aligned}
$$



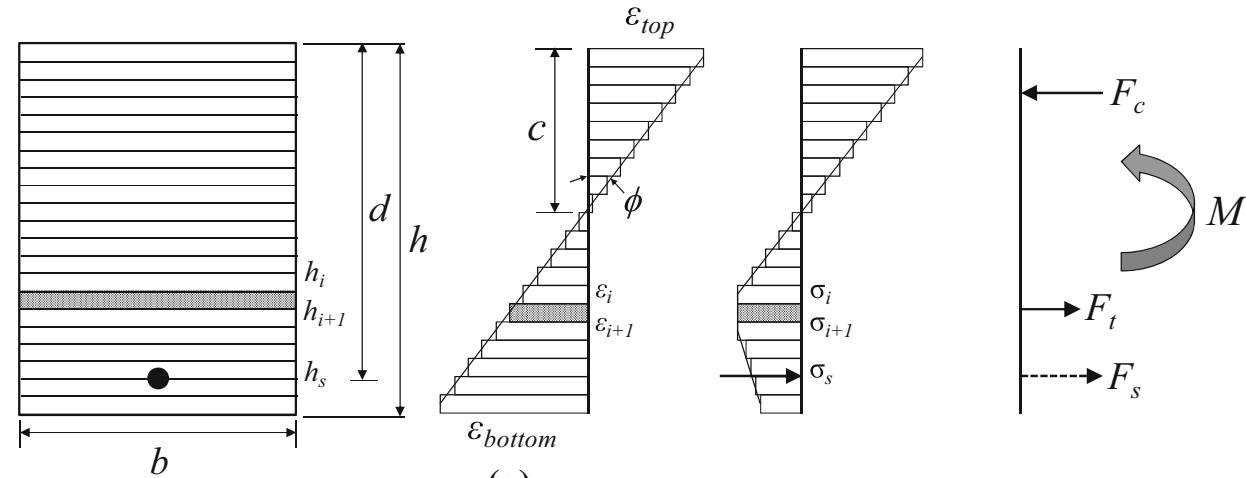

(a)

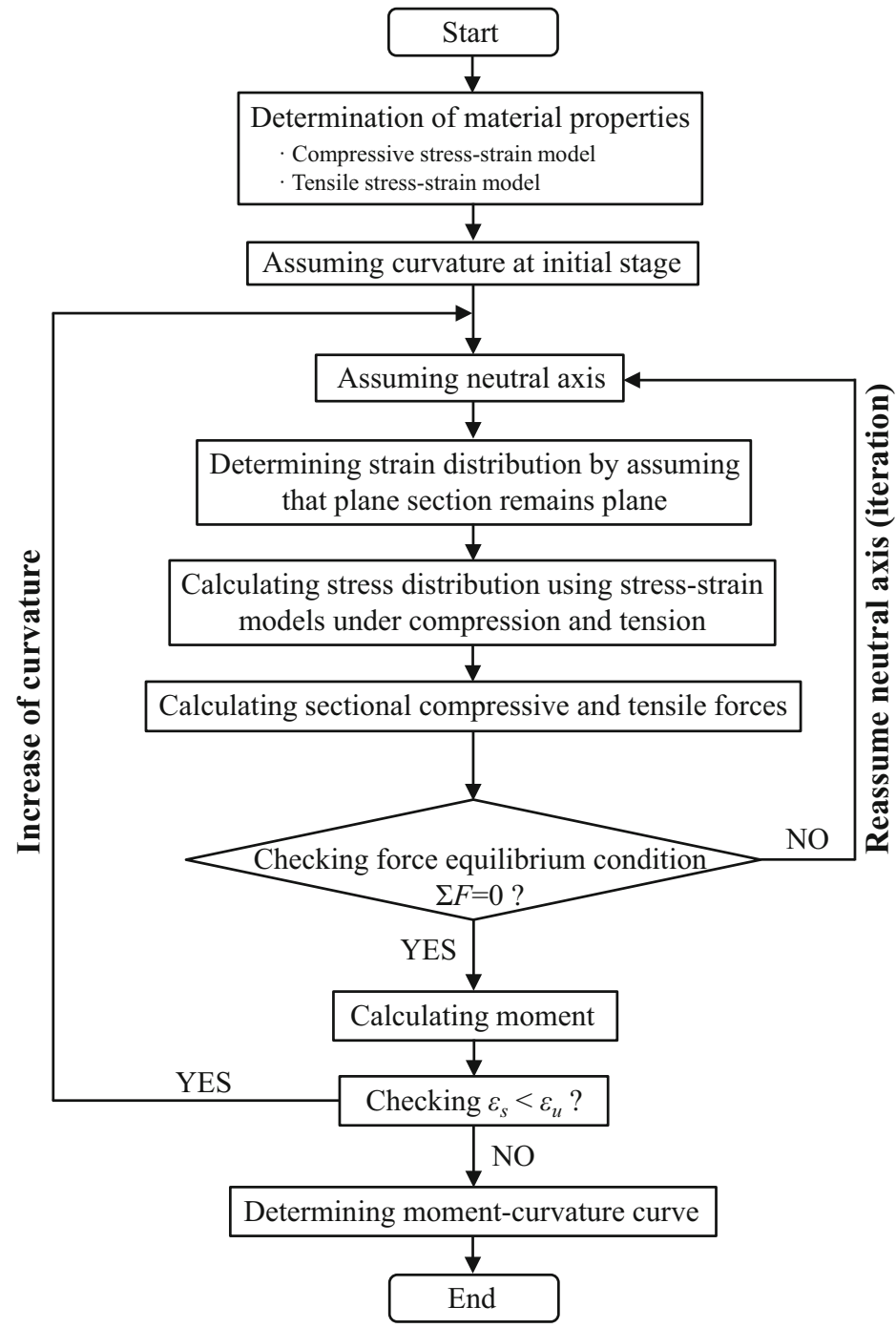

(b)

Fig. 15 Sectional analysis; a schematic description of stress and strain distributions in cross-section, $\mathbf{b}$ algorithm for sectional analysis (Yoo and Yoon 2015).

where $\varepsilon_{c r}$ is the factored elastic strain, $\varepsilon_{1}$ is the strain at the end of the initial plateau, $w_{1 k}$ is the crack opening displacement for which a certain stress level is retained after the first crack, $\varepsilon_{2}$ is the strain at zero tensile stress, and $w_{2 k}$ is the crack opening displacement at zero tensile stress.

Other material properties of the UHPFRC, proposed by the JSCE recommendations, are as follows:
- Coefficient of thermal expansion $\left(\times 10^{-6} /{ }^{\circ} \mathrm{C}\right)$ : 13.5 .

- Thermal conductivity $\left(\mathrm{kJ} / \mathrm{mh}^{\circ} \mathrm{C}\right): 8.3$.

- Thermal diffusivity $\left(\times 10^{-3} \mathrm{~m}^{2} / \mathrm{h}\right): 3.53$.

- Specific heat $\left(\mathrm{kJ} / \mathrm{kg}{ }^{\circ} \mathrm{C}\right): 0.92$.

- Total shrinkage: $550 \times 10^{-6}$.

- Creep coefficient: 0.4.

- Density $\left(\mathrm{kN} / \mathrm{m}^{3}\right)$ for calculating dead load: 25.5 .

- Poisson's ratio: 0.2 . 


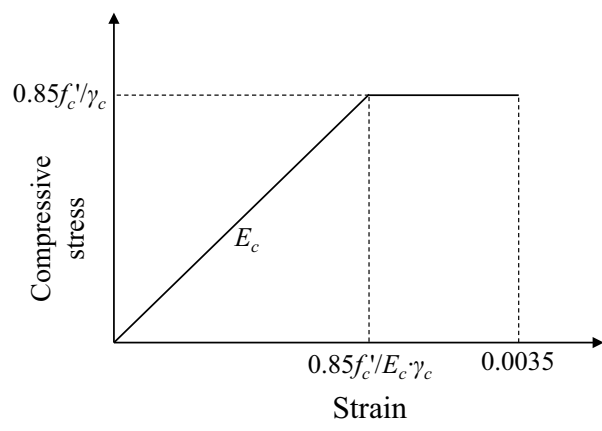

(a)

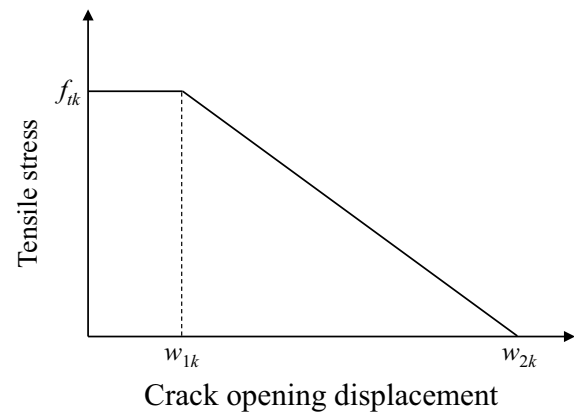

(b)

Fig. 16 Material models [JSCE recommendations (JSCE 2004)]; a compressive stress-strain curve, b tension-softening curve.

\subsubsection{Flexural Design}

In the JSCE recommendations, for the structural design of UHPFRC elements under bending, two simple assumptions are required to be satisfied: (1) the linear strain distribution and (2) the use of the proposed material models, as given in Fig. 16. The steel fiber contribution in the tensile zone after cracking needs to be considered in the structural design, and the compressive and tensile stress blocks in the cross-section should be considered based on the proposed material stress-strain models (Fig. 16) by considering the equivalent specific length for tension. Although a detailed procedure for calculating the ultimate moment capacity is not introduced in the JSCE recommendations, sectional analysis can be adopted for calculating the moment-curvature behavior of the UHPFRC elements (Yang et al. 2011; Yoo et al. 2016), similar to the case of the AFGC-SETRA recommendations.

\subsubsection{Shear Design}

For the shear design of the UHPFRC elements, the shear resistance from the matrix and the included steel fibers is required to be calculated. In accordance with the JSCE recommendations, the total shear resistance can be calculated by:

$$
V_{y d}=V_{r p c d}+V_{f d}+V_{p e d}
$$

where $V_{y d}$ is the total shear resistance of the reinforced UHPFRC beams, $V_{r p c d}$ is the shear resistance of the matrix without fiber, $V_{f d}$ is the shear resistance of the steel fibers, and $V_{\text {ped }}$ is the shear resistance of the stirrups.

Herein, $V_{r p c d}$ and $V_{p e d}$ are obtained by using Eqs. (21) and (22), respectively.

$$
\begin{aligned}
& V_{r p c d}=0.18 \sqrt{f_{c}^{\prime}} b_{w} d / \gamma_{b} \\
& V_{f d}=\left(f_{v d} / \tan \beta_{u}\right) b_{w} z / \gamma_{b}
\end{aligned}
$$

where $b_{w}$ is the web width of the beam, $d$ is the effective depth of the beam, $\gamma_{b}$ is the strength reduction factor $\left(\gamma_{b}=1.3\right), f_{v d}$ is the design tensile strength perpendicular to the diagonal crack $\left(=f_{t k} / \gamma_{b}\right), z$ is the distance between the point-acting compressive force and the center tensile reinforcement $(=d / 1.15)$, and $\beta_{u}$ is the inclination angle between the diagonal crack and the longitudinal direction of the beam. The inclination angle $\beta_{u}$ should be larger than $30^{\circ}$ and is calculated by $\beta_{u}=1 / 2 \tan ^{-1}\left[2 \tau /\left(\sigma_{x u}-\sigma_{y u}\right)\right]-\beta_{0}$, where $\tau$ is the average shear stress, $\sigma_{x u}$ and $\sigma_{y u}$ are the average compressive stress in longitudinal and transverse directions, and $\beta_{0}$ is the inclination angle without axial force.

In addition, $V_{\text {ped }}$ can be calculated as follows

$$
V_{p e d}=P_{e d} \sin \alpha_{p} / \gamma_{b}
$$

where $P_{e d}$ is the effective tensile force of the prestressing strand, $\alpha_{p}$ is the inclination angle between the prestressing strand and longitudinal axis of beam, and $\gamma_{b}$ is the strength reduction factor $\left(\gamma_{b}=1.1\right)$.

As was reported by Yang et al. (2012), the shear design of UHPFRC elements can be carried out by using both AFGCSETRA and JSCE recommendations, which provide good estimates with test data of I-shaped UHPFRC beams, as shown in Fig. 9.

\section{Field Applications of UHPFRC}

Due to its excellent mechanical performance, UHPFRC can lead to a reduction in the number of sections, the elimination of passive reinforcements, and the possibility for the design of structures that is not possible with ordinary concrete (NPCA 2011). For this reason, UHPFRC has attracted much attention from engineers for field applications from 1995 to 2010 (Voo et al. 2012). The representative application examples in North America, Europe, and Asia are briefly explained herein. The first structural application of UHPFRC was the prestressed hybrid pedestrian bridge at Sherbrooke in Canada, constructed in 1997 (Resplendino 2004) (Fig. 17a). This precast and prestressed pedestrian bridge includes a post-tensioned open-web space UHPFRC truss with 4 access spans made by conventional high-performance concrete. A ribbed slab with a 30-mm thickness was adopted, and a transverse prestressing was applied with sheathed monostrands. The UHPFRC truss webs were confined by steel tubes, and the structure was longitudinally prestressed by both internal and external prestressing strands. The total span length of the bridge was $60 \mathrm{~m}$, and 
the main span was assembled from six $10-\mathrm{m}$ prefabricated match-cast segments. The Bourg-lès-Valence bridge was the first UHPC road bridge in the world, built in France in 2001 (Hajar et al. 2004), as shown in Fig. 17b. The bridge was built from five assembled $\pi$-shaped precast UHPFRC beams, and the joints were made by in situ UHPFRC with internal reinforcements. The bridge consisted of two isolated spans with a length of approximately $20 \mathrm{~m}$, and all the $\pi$-shaped beams were prestressed without transverse passive reinforcement. The Seonyu Footbridge, completed in 2002 in Seoul, Korea, is currently the longest footbridge made by UHPFRC (Ductal ${ }^{\circledR}$ ) with a single span of $120 \mathrm{~m}$ and no central support (Fig. 17c). It consists of a $\pi$-shaped arch supporting a ribbed UHPFRC slab with a thickness of $30 \mathrm{~mm}$, and transverse prestressing was provided by sheathed monostrands. With equivalent load carrying capacity and strength properties, the bridge needed only half of the amount of materials required for conventional concrete construction (Voo et al. 2014). The first UHPFRC highway bridge, built in Iowa, USA, is the Mars Hill bridge, as shown in Fig. 17d. This is a simple single-span bridge consisting of three precast and prestressed concrete beams with a length of $33.5 \mathrm{~m}$ (modified 1.14-m-deep Iowa bulbtee beams), and the cast-in-place concrete bridge deck was topped. No stirrup was applied, and each beam included 47 low-relaxation prestressing strands with a diameter of $15.2 \mathrm{~mm}$ (Russell and Graybeal 2013).

Curved UHPFRC panels were applied to the building named the Atrium, which was built in Victoria, BC, Canada in 2013 (Fig. 18a) (NPCA 2011). In this project, UHPFRC was selected as an appropriate material for the curved panel system, due to its ability to form monolithically tight radial curves, and consequently, it could improve the energy efficiency of the building by eliminating unattractive seams and openings. The Community Center in Sedan, France was built in 2008 with a double skin facade to protect the glass fascia behind and to provide privacy using light blue UHPFRC perforated panels (Fig. 18b). They designed the UHPFRC panels to be $2 \mathrm{~m}$ by $4 \mathrm{~m}$ by $45 \mathrm{~mm}$ thick, to permit sunlight to stream through to the interior spaces. The main reason for choosing UHPFRC panels instead of traditional perforated panels, made of metal, painted steel, cast aluminum, cast iron, and stainless steel, was that UHPFRC is durable, and requires less energy consumption for fabrication and for maintenance over time (Henry et al. 2011).

Mega-architectural projects were carried out to build the Stade Jean Bouin and the MuCEM in France (Fig. 19) (NPCA 2011). In the case of the Stade Jean Bouin, the first application of a precast UHPFRC lattice-style facade system in the world was made. The $23,000 \mathrm{~m}^{2}$ envelope, which contains a $12,000 \mathrm{~m}^{2}$ roof, was built from 3600 selfsupporting UHPFRC panels that are 8-9 m long by $2.5 \mathrm{~m}$ wide, and $45 \mathrm{~mm}$ thick. The MuCEM consists of several types of precast UHPFRC structural elements, such as 78-m-long footbridge, main cubic structures with a $15,000 \mathrm{~m}^{2}$ surface area, flooring, and lattice-style envelope with a series of slender $\mathrm{N}$ - and Y-shaped columns. The architect designed the MuCEM to carry the entire external load by columns, and to satisfy the maximum requirements regarding both seismic and fire resistance, as specified by CSTB.
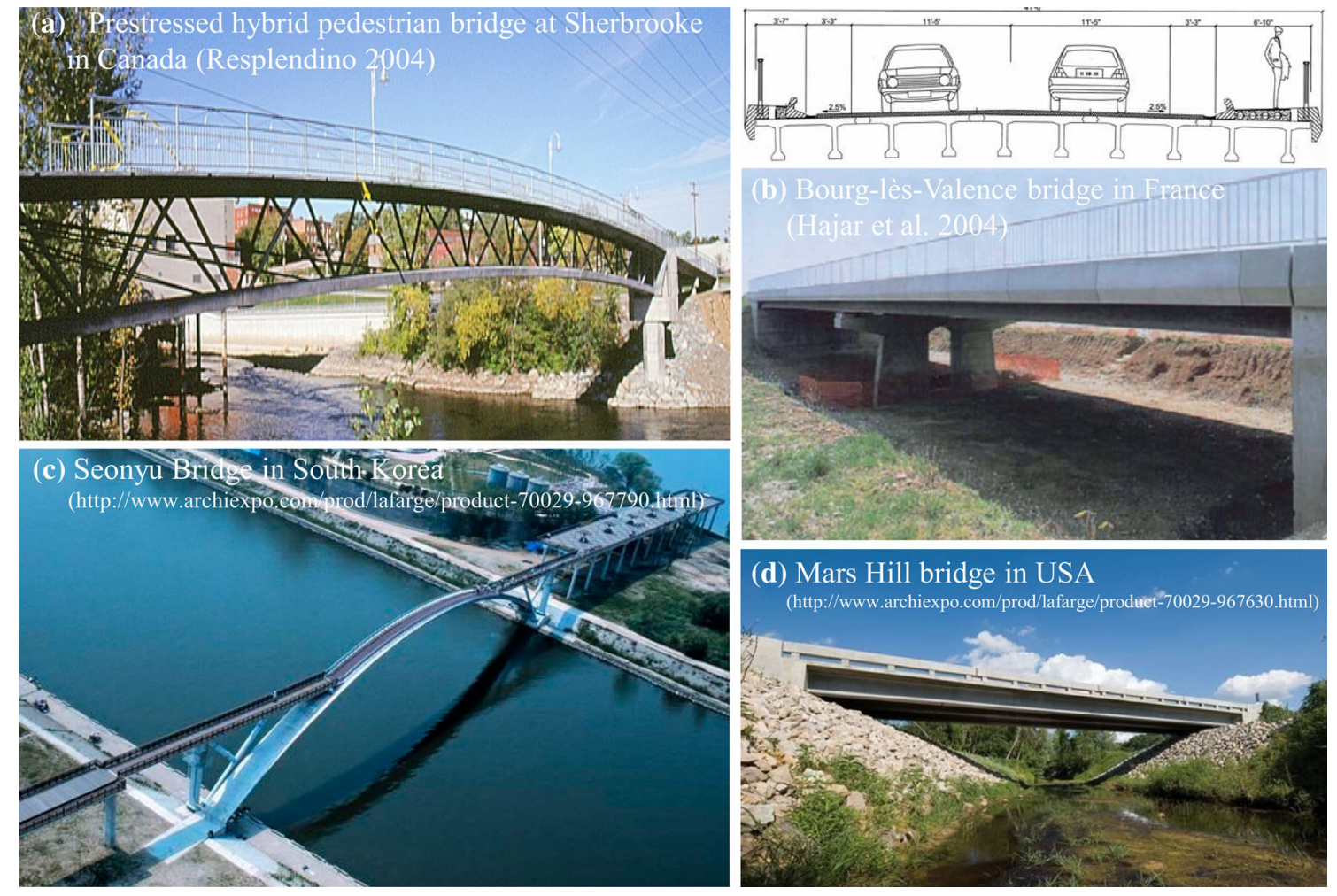

Fig. 17 Examples of UHPFRC applications in bridges. 

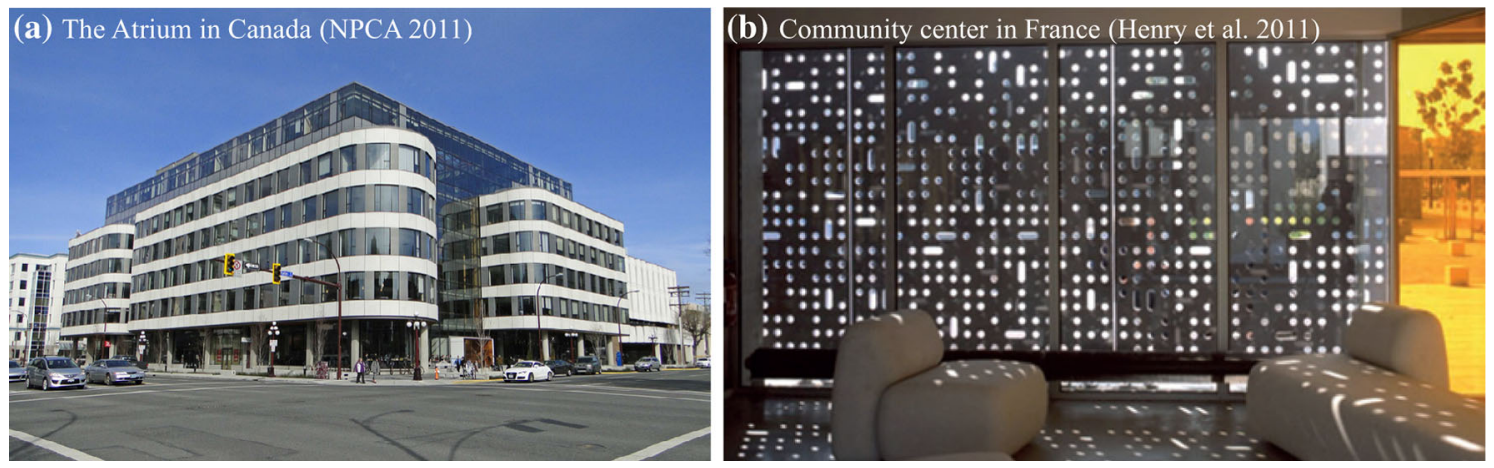

Fig. 18 Examples of UHPFRC applications in buildings.
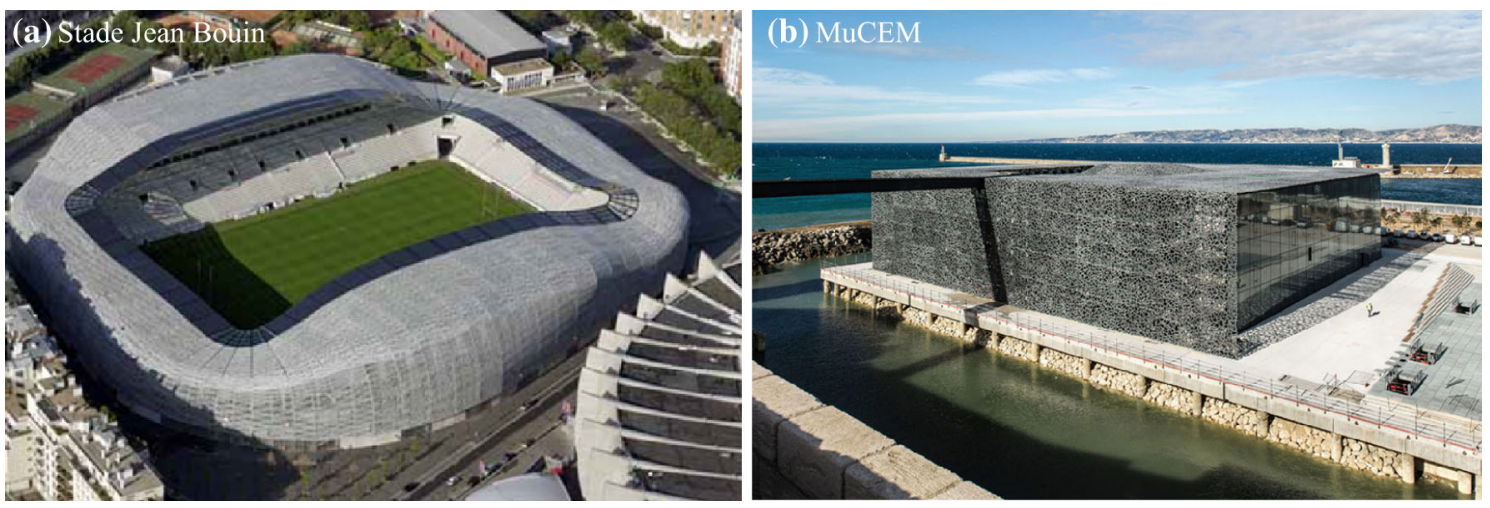

Fig. 19 Mega architectural projects in France (NPCA 2011).

\section{Conclusion}

This paper reviewed the current state-of-the-art for structural performance, design recommendations, and applications of UHPFRC. From the above literature review and discussions, the following conclusions are drawn:

(1) The use of $2 \%$ steel fibers resulted in a higher postcracking stiffness and ultimate load capacity of steel bar-reinforced UHPFRC beams, but it decreased their ductility because of the superb bond strength with steel bars and crack localization characteristics. Importantly, the use of UHPFRC was effective in overcoming the major drawbacks of conventional FRP-reinforced concrete structures (large service deflection) due to its strain-hardening response, and the use of CFRP bars was efficient in improving the flexural stiffness of reinforced UHPFRC beams, compared to that of GFRP bars. The hybrid reinforcements (steel + FRP bars), which have been adopted to reduce the service deflection of conventional FRP-reinforced beams, were ineffective in UHPFRC beams, and thus, the use of single FRP bars, instead of hybrid reinforcements, was recommended for the case of UHPFRC.

(2) With the inclusion of $2.5 \%$ steel fibers, approximately $250 \%$ higher shear strength was obtained, compared to that without fibers. The shear strength also increased with an increase in the fiber contents and a decrease in the shear span-to-depth ratio. Due to the excellent fiber bridging at crack surfaces, the shear failure of UHPFRC beams was less abrupt than the commonly seen shear failure mode in conventional concrete. In addition, both AFGC-SETRA and JSCE recommendations provided accurate predictions of shear strength of UHPFRC beams.

(3) The inclusion of steel fibers provided a better cracking performance, higher ultimate and cracking torque, and improved torsional stiffness. The higher ultimate torque was also found by increasing the ratios of stirrups and longitudinal rebars. The diagonal crack angle was influenced by the amount of stirrups and longitudinal rebars, whereas it was not affected by the amount of steel fibers.

(4) Better impact resistance of reinforced UHPFRC beams was obtained by including $2 \%$ steel fibers and a larger number of longitudinal steel bars. The residual capacity after impact damage was also improved by adding $2 \%$ steel fibers and using the longer steel fibers. UHPFRC columns exhibited significantly higher blast resistance such as lower maximum deflection, improved damage tolerance, and higher resistance, compared with the reinforced SCC and NC columns. Thus, it was noted that the application of UHPFRC in the structures subjected to blast loads is effective.

(5) Finally, the international design recommendations on UHPFRC were discussed minutely, and examples of practical applications of UHPFRC in architectural and civil structures were investigated. 


\section{Acknowledgments}

This research was supported by a grant from a Construction Technology Research Project 13SCIPS02 (Development of impact/blast resistant HPFRCC and evaluation technique thereof) funded by the Ministry of Land, Infrastructure and Transport.

\section{Open Access}

This article is distributed under the terms of the Creative Commons Attribution 4.0 International License (http://creativecommons.org/licenses/by/4.0/), which permits unrestricted use, distribution, and reproduction in any medium, provided you give appropriate credit to the original author(s) and the source, provide a link to the Creative Commons license, and indicate if changes were made.

\section{References}

ACI Committee 440. (2006). Guide for the design and construction of concrete reinforced with FRP bars (ACI 440.1R06). Farmington Hills, MI: American Concrete Institute.

AFGC-SETRA. (2002). Ultra high performance fibre-reinforced concretes. Interim recommendations. Bagneux, France: SETRA.

Ahmad Firas, S., Foret, G., \& Le Roy, R. (2011). Bond between carbon fibre-reinforced polymer (CFRP) bars and ultra high performance fibre reinforced concrete (UHPFRC): Experimental study. Construction and Building Materials, 25(2), 479-485.

American Concrete Institute (ACI). (2014). Building code requirements for structural concrete and commentary. ACI 318-14 and ACI 318R-14. Farmington Hills, MI: American Concrete Institute (ACI).

Aoude, H., Dagenais, F. P., Burrell, R. P., \& Saatcioglu, M. (2015). Behavior of ultra-high performance fiber reinforced concrete columns under blast loading. International Journal of Impact Engineering, 80, 185-202.

Astarlioglu, S., \& Krauthammer, T. (2014). Response of normal-strength and ultra-high-performance fiber-reinforced concrete columns to idealized blast loads. Engineering Structures, 61, 1-12.

Baby, F., Marchand, P., Atrach, M., \& Toutlemonde, F. (2013a). Analysis of flexure-shear behavior of UHPFRC beams based on stress field approach. Engineering Structures, 56, 194-206.

Baby, F., Marchand, P., \& Toutlemonde, F. (2013b). Shear behavior of ultrahigh performance fiber-reinforced concrete beams. I: Experimental investigation. Journal of Structural Engineering, 140(5), 04013111.

Baby, F., Marchand, P., \& Toutlemonde, F. (2013c). Shear behavior of ultrahigh performance fiber-reinforced concrete beams. II: Analysis and design provisions. Journal of Structural Engineering, 140(5), 04013112.
Bache, H. H. (1981). Densified cement ultra-fine particle-based materials. In Proceedings of the 2nd international conference on superplasticizers in concrete, Ottawa, Canada, p. 33.

Bertram, G., \& Hegger, J. (2012). Shear behavior of pretensioned UHPC beams-Tests and design. In Proceedings of the third international symposium on UHPC and nanotechnology for high performance construction materials, Kassel, pp. 493-500.

Birchall, J. D., Howard, A. J., \& Kendall, K. (1981). Flexural strength and porosity of cements. Nature, 289(5796), 388-390.

CAN/CSA S806. (2002). Design and construction of building components with fibre reinforced polymers, Rexdale, Canada.

CAN/CSA-S6. (2006). Canadian highway bridge design code, Toronto, ON.

CEB-FIP. (1993). Model code for concrete structures. CEB Bulletin d'Information. Comite Euro international du Beton, Lausanne, Switzerland.

Choi, W. C., Yun, H. D., Cho, C. G., \& Feo, L. (2014). Attempts to apply high performance fiber-reinforced cement composite (HPFRCC) to infrastructures in South Korea. Composite Structures, 109, 211-223.

Cosenza, E., Manfredi, G., \& Realfonzo, R. (1995). Analytical modelling of bond between FRP reinforcing bars and concrete. In L. Taerwe (Ed.), Proceedings of second international RILEM symposium (FRPRCS-2) (pp. 164-171). London, UK: E and FN Spon.

DAfStB UHPC. (2003). State-of-the-art report on ultra high performance concrete-Concrete technology and design. Deutscher Ausschuss für Stahlbeton/German Association for Reinforced Concrete, Berlin, Germany, draft 3.

Dancygier, A. N., \& Berkover, E. (2016). Cracking localization and reduced ductility in fiber-reinforced concrete beams with low reinforcement ratios. Engineering Structures, 111, 411-424.

Empelmann, M., \& Oettel, V. (2012). UHPFRC box girders under torsion. In Proceedings of the third international symposium on UHPC and nanotechnology for high performance construction materials, Kassel, Germany, pp. 517-524.

Farhat, F. A., Nicolaides, D., Kanellopoulos, A., \& Karihaloo, B. L. (2007). High performance fibre-reinforced cementitious composite (CARDIFRC) - Performance and application to retrofitting. Engineering Fracture Mechanics, 74(1-2), 151-167.

Fehling, E., \& Ismail, M. (2012). Experimental investigations on UHPC structural elements subjected to pure torsion. In Proceedings of the third international symposium on UHPC and nanotechnology for high performance construction materials, Kassel, Germany, pp. 501-508.

Ferrier, E., Labossiere, P., \& Neale, K. W. (2009). Mechanical behavior of an innovative hybrid beam made of glulam and ultrahigh-performance concrete reinforced with FRP or steel. Journal of Composites for Construction, 14(2), 217-223.

Ferrier, E., Michel, L., Zuber, B., \& Chanvillard, G. (2015). Mechanical behaviour of ultra-high-performance short- 
fibre-reinforced concrete beams with internal fibre reinforced polymer bars. Composites Part B: Engineering, 68, 246-258.

Fujikake, K., Senga, T., Ueda, N., Ohno, T., \& Katagiri, M. (2006a). Study on impact response of reactive powder concrete beam and its analytical model. Journal of Advanced Concrete Technology, 4(1), 99-108.

Fujikake, K., Senga, T., Ueda, N., Ohno, T., \& Katagiri, M. (2006b). Effects of strain rate on tensile behavior of reactive powder concrete. Journal of Advanced Concrete Technology, 4(1), 79-84.

Fujikake, K., Uebayashi, K., Ohno, T., Shimoyama, Y., \& Katagiri, M. (2008). Dynamic properties of steel fiber reinforced mortar under high-rates of loadings and triaxial stress states. In Proceedings of the 7th international conference on structures under shock and impact (pp. 437-446). Montreal, Canada: WIT Press.

Graybeal, B. A. (2008). Flexural behavior of an ultrahigh-performance concrete I-girder. Journal of Bridge Engineering, 13(6), 602-610.

Graybeal, B., \& Tanesi, J. (2007). Durability of an ultrahighperformance concrete. Journal of Materials in Civil Engineering, 19(10), 848-854.

Hajar, Z., Lecointre, D., Simon, A., \& Petitjean, J. (2004). Design and construction of the world first ultra-high performance concrete road bridges. In Proceeding of the international symposium on ultra high performance concrete, University of Kassel, Kassel, Germany, pp. 39-48.

Henry, K. A., Seibert, P. J., \& America, L. N. (2011). Manufacturing UHPC architectural products. http://www.ductal. fr/CPI_-_OCTOBER_2011.pdf.

Jaeger, G. L., Tadros, G., \& Mufti, A. A. (1995). Balanced section, ductility and deformability in concrete with FRP reinforcement. Technical report no. 2-1995, Nova Scotia computer aided design/computer aided manufacturing centre, Technical University of Nova Scotia, Halifax, Canada.

JSCE. (2004). Recommendations for design and construction of ultra-high strength fiber reinforced concrete structures (Draft). Tokyo, Japan: Japan Society of Civil Engineers.

Jungwirth, J., \& Muttoni, A. (2004). Structural behavior of tension members in UHPC. In Proceedings of the international symposium on ultra-high-performance concrete, Kassel, Germany, pp. 533-544.

KCI. (2012). Design recommendations for ultra-high performance concrete K-UHPC. KCI-M-12-003. Seoul: Korea Concrete Institute.

Kim, S. W., Park, J. J., Kang, S. T., Ryo, G. S., \& Koh, K. T. (2008). Development of ultra high performance cementitious composites (UHPCC) in Korea. In Proceedings of the fourth international IABMAS conference, Seoul, Korea, p. 110 .

Lau, D., \& Pam, H. J. (2010). Experimental study of hybrid FRP reinforced concrete beams. Engineering Structures, 32(12), 3857-3865.

Li, H., \& Liu, G. (2016). Tensile properties of hybrid fiberreinforced reactive powder concrete after exposure to elevated temperatures. International Journal of Concrete Structures and Materials, 10(1), 29-37.

Livermore Software Technology Corporation. (2007). LS-DYNA user's manual-Version 971. Livermore, CA: Livermore Software Technology Corporation.

Mao, L., Barnett, S., Begg, D., Schleyer, G., \& Wight, G. (2014). Numerical simulation of ultra high performance fibre reinforced concrete panel subjected to blast loading. International Journal of Impact Engineering, 64, 91-100.

NPCA White Paper. (2011). Ultra high performance concrete (UHPC), guide to manufacturing architectural precast UHPC elements. http://precast.org/wp-content/uploads/ 2011/05/NPCA-ultra-high-performance-concrete.pdf

Orange, G., Acker, P., \& Vernet, C. (1999). A new generation of UHP concrete: Ductal ${ }^{\circledR}$ damage resistance and micromechanical analysis. In Proceedings of the third international workshop on high performance fiber reinforced cement composites (HPFRCC3), Mainz, Germany, pp. 101-111.

Resplendino, J. (2004). First recommendations for ultra-highperformance concretes and examples of application. In Proceeding of the international symposium on ultra high performance concrete, University of Kassel, Kassel, Germany, pp. 79-90.

Richard, P., \& Cheyrezy, M. (1995). Composition of reactive powder concretes. Cement and Concrete Research, 25(7), 1501-1511.

RILEM TC. (1994). RILEM recommendations for the testing and use of constructions materials. RC 6 bond test for reinforcement steel. 2. Pull-out test, 1983 (pp. 218-220). London, UK: E \& FN SPON.

Roy, D. M., Gouda, G. R., \& Bobrowsky, A. (1972). Very high strength cement pastes prepared by hot pressing and other high pressure techniques. Cement and Concrete Research, 2(3), 349-366.

Russell, H. G., \& Graybeal, B. A. (2013). Ultra-high performance concrete: A state-of-the-art report for the bridge community, FHWA-HRT-13-060.

Saleem, M. A., Mirmiran, A., Xia, J., \& Mackie, K. (2011). Ultra-high-performance concrete bridge deck reinforced with high-strength steel. ACI Structural Journal, 108(5), 601-609.

Schäfers, M., \& Seim, W. (2011). Investigation on bonding between timber and ultra-high performance concrete (UHPC). Construction and Building Materials, 25(7), 3078-3088.

Tadepalli, P. R., Dhonde, H. B., Mo, Y. L., \& Hsu, T. T. (2015). Shear strength of prestressed steel fiber concrete I-beams. International Journal of Concrete Structures and Materials, 9(3), 267-281.

Tam, C. M., Tam, V. W., \& Ng, K. M. (2012). Assessing drying shrinkage and water permeability of reactive powder concrete produced in Hong Kong. Construction and Building Materials, 26(1), 79-89.

Voo, Y. L., Foster, S. J., \& Voo, C. C. (2014). Ultrahigh-performance concrete segmental bridge technology: Toward sustainable bridge construction. Journal of Bridge Engineering, 20(8), B5014001. 
Voo, Y. L., Nematollahi, B., Said, A., Gopal, A., \& Yee, T. Y. (2012). Application of ultra high performance fiber reinforced concrete-The Malaysia perspective. International Journal of Sustainable Construction Engineering and Technology, 3(1), 26-44.

Voo, Y. L., Poon, W. K., \& Foster, S. J. (2010). Shear strength of steel fiber-reinforced ultrahigh-performance concrete beams without stirrups. Journal of Structural Engineering, 136(11), 1393-1400.

Wambeke, B. W., \& Shield, C. K. (2006). Development length of glass fiber-reinforced polymer bars in concrete. $A C I$ Structural Journal, 103(1), 11-17.

Wu, C., Oehlers, D. J., Rebentrost, M., Leach, J., \& Whittaker, A. S. (2009). Blast testing of ultra-high performance fibre and FRP-retrofitted concrete slabs. Engineering Structures, 31(9), 2060-2069.

Xia, J., Mackie, K. R., Saleem, M. A., \& Mirmiran, A. (2011). Shear failure analysis on ultra-high performance concrete beams reinforced with high strength steel. Engineering Structures, 33(12), 3597-3609.

Yang, I. H., Joh, C., \& Kim, B. S. (2010). Structural behavior of ultra high performance concrete beams subjected to bending. Engineering Structures, 32(11), 3478-3487.

Yang, I. H., Joh, C., \& Kim, B. S. (2011). Flexural strength of large-scale ultra high performance concrete prestressed T-beams. Canadian Journal of Civil Engineering, 38(11), 1185-1195.

Yang, I. H., Joh, C., Lee, J. W., \& Kim, B. S. (2012). An experimental study on shear behavior of steel fiber-reinforced ultra high performance concrete beams. Journal of The Korean Society of Civil Engineers, 32(1A), 55-64.

Yang, I. H., Joh, C., Lee, J. W., \& Kim, B. S. (2013). Torsional behavior of ultra-high performance concrete squared beams. Engineering Structures, 56, 372-383.

Yi, N. H., Kim, J. H. J., Han, T. S., Cho, Y. G., \& Lee, J. H. (2012). Blast-resistant characteristics of ultra-high strength concrete and reactive powder concrete. Construction and Building Materials, 28(1), 694-707.

Yoo, D. Y., \& Banthia, N. (2015). Numerical simulation on structural behavior of UHPFRC beams with steel and GFRP bars. Computers and Concrete, 16(5), 759-774.

Yoo, D. Y., Banthia, N., Kim, S. W., \& Yoon, Y. S. (2015a). Response of ultra-high-performance fiber-reinforced concrete beams with continuous steel reinforcement subjected to low-velocity impact loading. Composite Structures, 126 , 233-245.

Yoo, D. Y., Banthia, N., \& Yoon, Y. S. (2016). Flexural behavior of ultra-high-performance fiber-reinforced concrete beams reinforced with GFRP and steel rebars. Engineering Structures, 111, 246-262.

Yoo, D. Y., Kang, S. T., \& Yoon, Y. S. (2014a). Effect of fiber length and placement method on flexural behavior, tensionsoftening curve, and fiber distribution characteristics of UHPFRC. Construction and Building Materials, 64, $67-81$.

Yoo, D. Y., Kwon, K. Y., Park, J. J., \& Yoon, Y. S. (2015b). Local bond-slip response of GFRP rebar in ultra-highperformance fiber-reinforced concrete. Composite Structures, 120, 53-64.

Yoo, D. Y., Park, J. J., Kim, S. W., \& Yoon, Y. S. (2014b). Influence of reinforcing bar type on autogenous shrinkage stress and bond behavior of ultra high performance fiber reinforced concrete. Cement and Concrete Composites, 48, $150-161$

Yoo, D. Y., Shin, H. O., Yang, J. M., \& Yoon, Y. S. (2014c). Material and bond properties of ultra high performance fiber reinforced concrete with micro steel fibers. Composites Part B: Engineering, 58, 122-133.

Yoo, D. Y., \& Yoon, Y. S. (2015). Structural performance of ultra-high-performance concrete beams with different steel fibers. Engineering Structures, 102, 409-423.

Yoo, D. Y., Yoon, Y. S., \& Banthia, N. (2015c). Impact and residual capacities of ultra-high-performance concrete beams with steel rebars. In Proceedings of the fifth international workshop on performance, protection \& strengthening of structures under extreme loading, East Lansing, MI.

Yoon, Y. S., Yang, J. M., Min, K. H., \& Shin, H. O. (2011). Flexural strength and deflection characteristics of highstrength concrete beams with hybrid FRP and steel rebar reinforcement. In Proceedings of the 10th symposium on fiber reinforced polymer reinforcement for concrete structures (FRPRCS-10), SP-275-04, American Concrete Institute, Farmington Hills, MI, pp. 1-22.

Yudenfreund, M., Odler, I., \& Brunauer, S. (1972). Hardened portland cement pastes of low porosity I. Materials and experimental methods. Cement and Concrete Research, 2(3), 313-330. 